\title{
ID01 suppresses inhibitor development in hemophilia A treated with factor VIII
}

\author{
Davide Matino, ${ }^{1}$ Marco Gargaro, ${ }^{1}$ Elena Santagostino, ${ }^{2}$ Matteo N.D. Di Minno, ${ }^{3}$ Giancarlo Castaman, ${ }^{4,5}$ Massimo Morfini, ${ }^{5}$ \\ Angiola Rocino, ${ }^{6}$ Maria E. Mancuso, ${ }^{2}$ Giovanni Di Minno, ${ }^{3}$ Antonio Coppola, ${ }^{3}$ Vincenzo N. Talesa, ${ }^{1}$ Claudia Volpi, ${ }^{1}$ Carmine Vacca, ${ }^{1}$ \\ Ciriana Orabona, ${ }^{1}$ Rossana lannitti, ${ }^{1}$ Maria G. Mazzucconi, ${ }^{7}$ Cristina Santoro, ${ }^{7}$ Antonella Tosti, ${ }^{8}$ Sara Chiappalupi, ${ }^{1}$ \\ Guglielmo Sorci, ${ }^{1}$ Giuseppe Tagariello, ${ }^{9}$ Donata Belvini, ${ }^{9}$ Paolo Radossi, ${ }^{9}$ Raffaele Landolfi, ${ }^{10}$ Dietmar Fuchs, ${ }^{11}$ Louis Boon, ${ }^{12}$ \\ Matteo Pirro, ${ }^{13}$ Emanuela Marchesini, ${ }^{13}$ Ursula Grohmann, ${ }^{1}$ Paolo Puccetti, ${ }^{1}$ Alfonso lorio, ${ }^{14}$ and Francesca Fallarino ${ }^{1}$
}

'Department of Experimental Medicine, University of Perugia, Perugia, Italy. ${ }^{2}$ Angelo Bianchi Bonomi Hemophilia and Thrombosis Centre, Fondazione IRCCS Cà Granda, Ospedale Maggiore Policlinico, Milan, Italy. ${ }^{3}$ Regional Reference Centre for Coagulation Disorders, Department of Clinical and Experimental Medicine, Federico II University, Naples, Italy. ${ }^{4}$ Department of Cell Therapy and Hematology, San Bortolo Hospital, Vicenza, Italy. ${ }^{5}$ Centro Emofilia, Azienda Ospedaliera Careggi, Florence, Italy. ${ }^{6}$ Hemophilia and Thrombosis Centre, San Giovanni Bosco Hospital, Naples, Italy. ${ }^{7}$ Department of Cellular Biotechnology and Hematology, La Sapienza University, Rome, Italy. ${ }^{8}$ Department of Medicine, University of Perugia, Perugia, Italy. ${ }^{9}$ Transfusion Service, Hemophilia and Regional Blood Disease Centre, Castelfranco Veneto, Italy. ${ }^{10}$ Institute of Internal Medicine and Geriatrics, Hemostasis Research Center, Catholic University, Rome, Italy. "Division of Biological Chemistry, Biocenter, Innsbruck Medical University, Innsbruck, Austria. ${ }^{12}$ Bioceros, Utrecht, Netherlands. ${ }^{13}$ Department of Medicine, Perugia, Italy. ${ }^{14}$ Departments of Clinical Epidemiology and Biostatistics and Medicine, McMaster University, Hamilton, Ontario, Canada.

The development of inhibitory antibodies to factor VIII (FVIII) is a major obstacle in using this clotting factor to treat individuals with hemophilia A. Patients with a congenital absence of FVIII do not develop central tolerance to FVIII, and therefore, any control of their FVIII-reactive lymphocytes relies upon peripheral tolerance mechanisms. Indoleamine 2,3-dioxygenase 1 (IDO1) is a key regulatory enzyme that supports Treg function and peripheral tolerance in adult life. Here, we investigated the association between IDO1 competence and inhibitor status by evaluating hemophilia A patients harboring F8-null mutations that were either inhibitor negative $(n=50)$ or positive $(n=50)$. We analyzed ID01 induction, expression, and function for any relationship with inhibitor occurrence by multivariable logistic regression and determined that defective TLR9-mediated activation of IDO1 induction is associated with an inhibitor-positive status. Evaluation of experimental hemophilic mouse models with or without functional IDO1 revealed that tryptophan metabolites, which result from ID01 activity, prevent generation of anti-FVIII antibodies. Moreover, treatment of hemophilic animals with a TLR9 agonist suppressed FVIII-specific B cells by a mechanism that involves ID01-dependent induction of Tregs. Together, these findings indicate that strategies aimed at improving ID01 function should be further explored for preventing or eradicating inhibitors to therapeutically administered FVIII protein.

\section{Introduction}

Appropriate management of bleeding episodes in severe hemophilia A patients requires replacement therapy, namely, the prophylactic, intravenous administration of factor VIII (FVIII), to restore hemostasis (1). The occurrence of neutralizing antibodies (or inhibitors) to exogenous FVIII represents a major drawback of replacement therapy in terms of mortality, morbidity, and societal cost (2). Several risk factors for inhibitor development have been identified, but the underlying mechanism - thought to be multifactorial - is not completely understood (3-5). Mutations resulting in the absence (or severe truncation) of the FVIII protein

Authorship note: Alfonso lorio and Francesca Fallarino are co-senior authors Conflict of interest: Angiola Rocino has attended advisory board meetings of Baxter, Novo Nordisk, and Pfizer; she also acted as a paid consultant for Bayer, CSL Behring, Kedrion, Novo Nordisk, and Pfizer and received fees as a speaker in meetings organized by Baxter, Bayer, CSL Behring, Novo Nordisk, and Pfizer. Alfonso lorio has received research and consultancy funds from Baxter, Novo Nordisk, Bayer, Biogen, and Pfizer. All funds were directed to McMaster University, and none was received for the present work. Submitted: March 13, 2015; Accepted: July 23, 2015.

Reference information: / Clin Invest. 2015;125(10):3766-3781. doi:10.1172/JCI81859. are associated with the highest risk of inhibitor formation in that those mutations prevent a patient's immune system from initiating early, central tolerance to FVIII (6-8). Inhibitors, however, occur only in a limited proportion of those patients treated with clotting factor concentrates, and FVIII-reactive cells are found in inhibitor-free patients and in healthy subjects as well (9). This suggests that the immunogenicity of FVIII is not absolutely contingent on a lack of central tolerance and that effective regulatory mechanisms of peripheral tolerance must operate extrathymically in most patients harboring FVIII-reactive lymphocytes (10).

Indoleamine 2,3-dioxygenase 1 (IDO1) is an inducible, hemecontaining protein that catalyzes the initial step in tryptophan degradation along the so-called kynurenine pathway (11). IDO1 has both enzymic and nonenzymic regulatory functions (12), and it is a pivotal component of a complex, pleiotropic system that allows long-term control of immune homeostasis in adult life $(13,14)$. In several experimental settings, the expression of functional IDO1 by DCs results in tolerogenic effects, flexibly modulated by environmental factors, including danger signals recognized by TLRs $(15,16)$. Although TLR activation typically leads 


\section{Table 1. Patient baseline characteristics $(n=100)$}

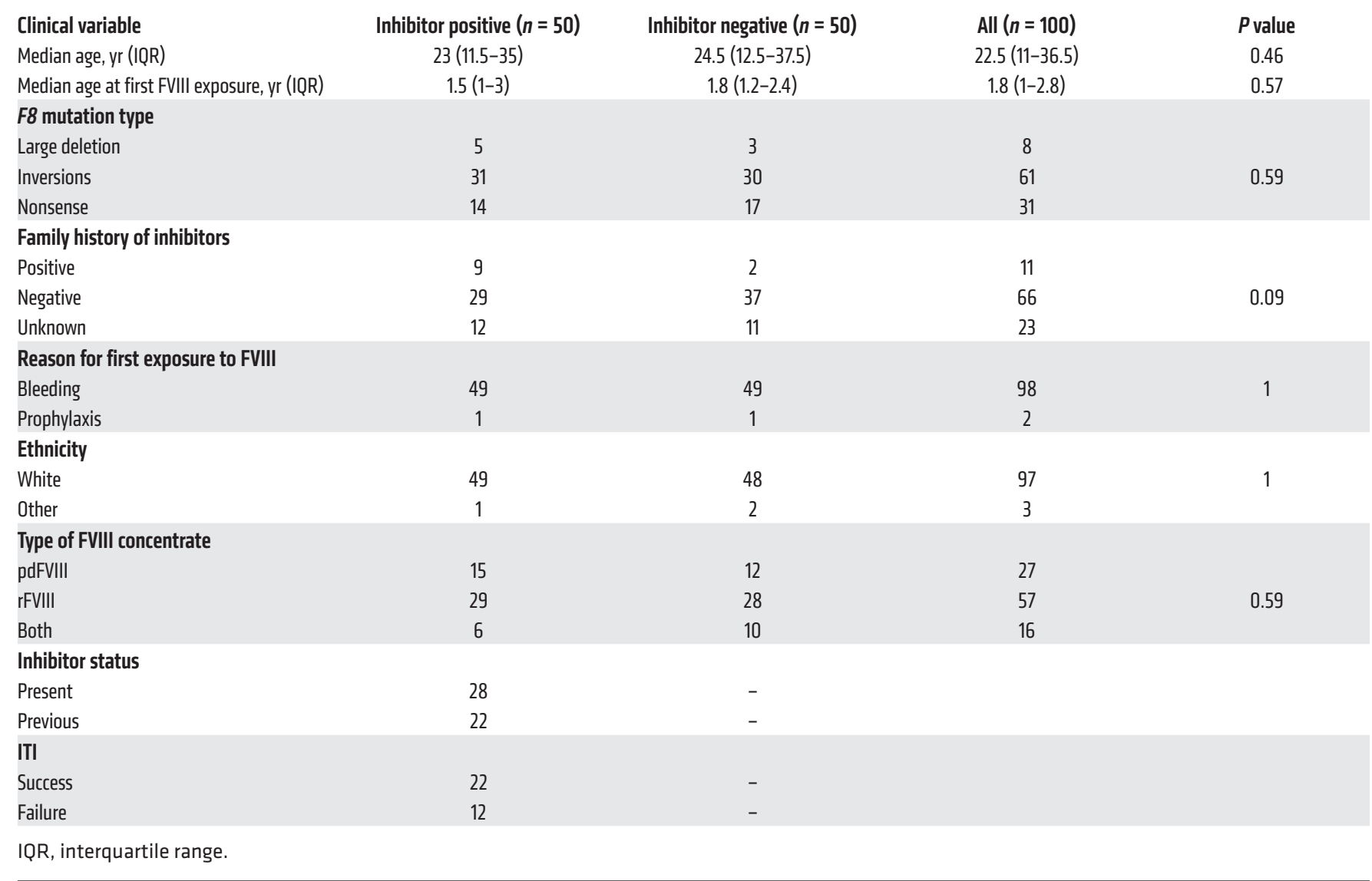

to protective immunity, it can also elicit counterregulatory, IDO1dependent effects meant to avoid hyperinflammatory and/or autoimmune responses $(17,18)$. As such, IDO1 is a crucial means of inducing and sustaining the function of Tregs, which preside over the postnatal acquisition of peripheral tolerance $(12,19)$. In both humans and mice, the immunosuppressive activity of TLR9 agonists - such as CpG-rich oligodeoxynucleotides (CpG-ODNs) that mimic danger signals - has been attributed to the regulatory function of IDO1 (20). In experimental hemophilia A, a potentially protective role for high-dose CpG-ODN against anti-FVIII antibody development has been documented through thus far unknown mechanisms (21).

The role of IDO1 in peripheral tolerance raises the question of whether IDO1 has any role in restraining FVIII-specific responses, also with a view to preventing or eradicating inhibitors in hemophilia A patients. Along this as-yet-unexplored direction, we investigated IDO1 expression and function - in response to $\mathrm{CpG}-\mathrm{ODN}$ stimulation in hemophilic patients, with or without inhibitors, as well as an in an experimental setting of hemophilia A. In patients, we found a strong and statistically significant association between failure to activate IDO1 in response to $\mathrm{CpG}-\mathrm{ODN}$ and the presence of inhibitors. In hemophilic mice, CpG inhibited the activation of FVIII-specific memory B cells and their differentiation into antibody-secreting plasma cells both in vitro and in vivo, and the effect required functional IDO1. These data may lead to innovative means of opposing FVIII-specific antibody production in patients on replacement therapy with FVIII.

\section{Results}

Defective IDO1 induction in inhibitor-positive patients. We enrolled 100 severe hemophilia A patients, of which 50 were inhibitor positive, and 34 of those patients underwent immune tolerance induction (ITI), with a protocol consisting of daily, high-dose FVIII concentrate administration. Of the 34 patients, 22 were successfully tolerized, and 12 were not. The remaining 16 inhibitor-positive patients were not subjected to ITI. Patient characteristics are summarized in Table 1. Baseline characterization of the major cell subsets in peripheral blood mononuclear cells (PBMCs) showed no quantitative differences between inhibitor-positive and inhibitornegative patients (Supplemental Table 1; supplemental material available online with this article; doi:10.1172/JCI81859DS1). We investigated IDO1 expression and function in response to CpGODN stimulation - in those patients, with or without inhibitors.

In preliminary experiments not reported here, we found that unfractionated peripheral PBMCs from hemophilic patients with or without anti-FVIII antibodies showed no differences in basal IDO1 expression. When PBMCs were treated with CpG-ODN ( $3 \mu \mathrm{g} / \mathrm{ml}$ for 48 hours), significant IDO1 induction was found in inhibitor-negative relative to inhibitor-positive patients by 
$\square$ Anti-FVIII ab positive patients

Anti-FVIII ab negative patients
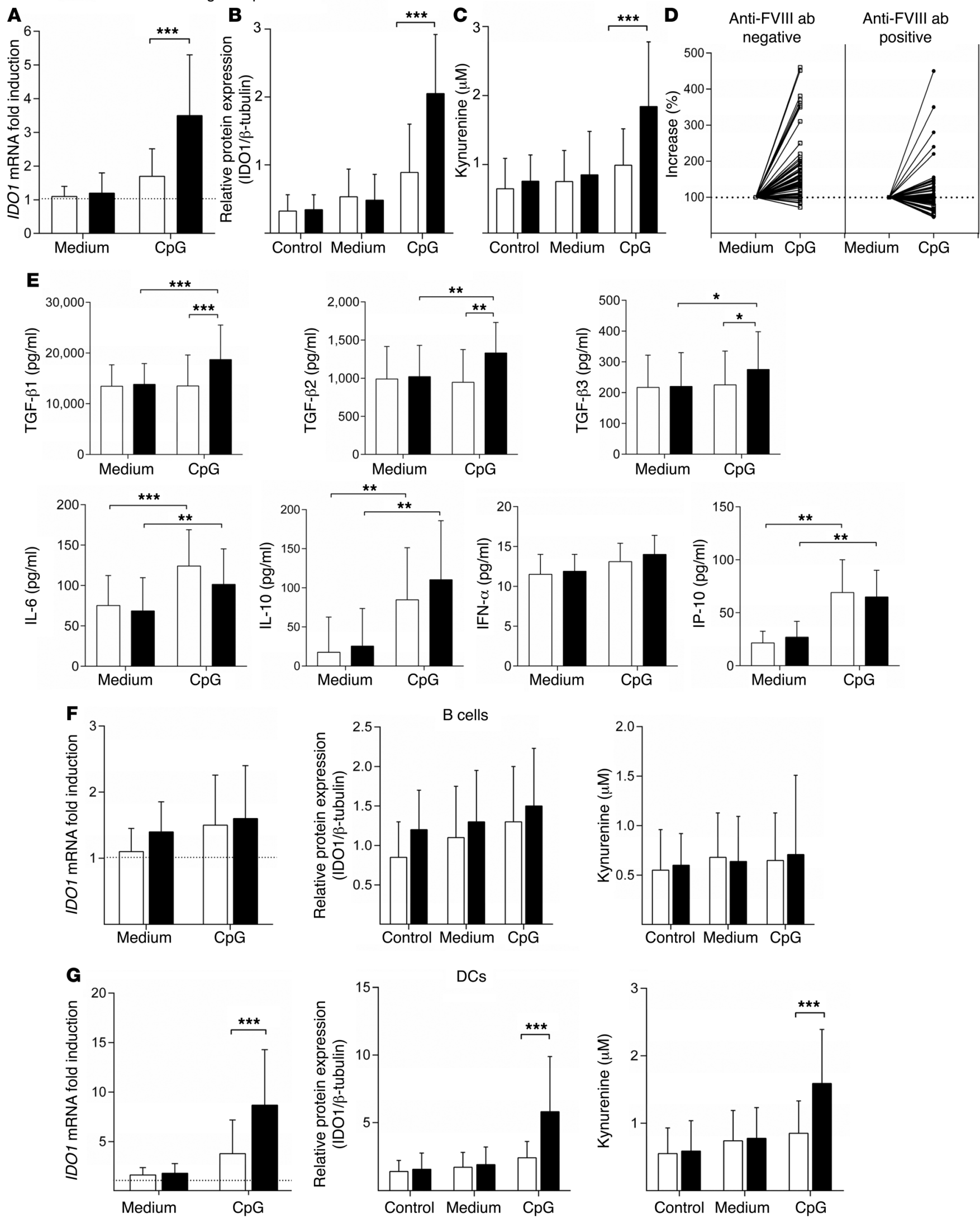
Figure 1. ID01 induction by CPG-ODN in severe hemophilia $A$ patients with $(\boldsymbol{n}=\mathbf{5 0})$ or without $(\boldsymbol{n}=\mathbf{5 0})$ inhibitors. (A) PBMCs were cultured with CpG-ODN or medium alone. Expression of mRNA is presented relative to expression in the respective control, freshly harvested PBMCs from inhibitor-negative patients (in which fold change $=1$; dotted line). (B) IDO1 protein expression was quantified by densitometry, with $\beta$-tubulin normalization. (C) PBMCs from inhibitor-positive and inhibitor-free patients were cultured with $\mathrm{CpG}$ or medium alone. Culture supernatants were collected after 48 hours, and L-kynurenine was measured by HPLC. (D) L-kynurenine increase (\%) in individual patients of either group. (E) Cytokine production by PBMCs cultured with CpG-ODN or medium alone. Supernatants were collected and analyzed for cytokine production after 24 (IL-6) or 48 hours (TCF- $\beta 1$, TGF- $\beta 2$, TCF- $\beta 3$, IL-10, IFN- $\alpha$, IP-10). ID01 transcript and protein expressions and kynurenine production were quantified in $B$ cells $(\mathbf{F})$ as well as in unfractionated DCs (G). In all panels, data represent mean \pm SD. ${ }^{*} P<0.05 ;{ }^{*} P<0.01 ;{ }^{* *} P<0.001$, ANOVA and Bonferroni's multiple comparison test.

reverse-transcriptase PCR (RT-PCR) assessment of IDO1 transcripts (Figure 1A), by immunoblot analysis of protein expression (Figure 1B), and by measurements of enzymic activity (Figure 1, $\mathrm{C}$ and $\mathrm{D})$. Differences in all of the above comparisons were highly significant $(P<0.001)$. Overall, $36(72 \%)$ out of the 50 inhibitorfree patients showed upregulated IDO1 expression and function in response to CpG-ODN stimulation, whereas only 18 (36\%) of the 50 inhibitor-positive patients were capable of upregulating IDO1 under the same stimulation conditions (Supplemental Table 2).

None of the patient and treatment characteristics that might affect inhibitor development - and that we were aware of - were associated with IDO1 competence. In particular, neither ITI treatment nor duration of inhibitor presence was associated with IDO1 functionality. The inhibitor-positive status was significantly associated with family history of inhibitors (odds ratio $[\mathrm{OR}]=5.37$; 95\% CI, 1.06-27.24), with previous use of recombinant concentrates $(\mathrm{OR}=2.52 ; 95 \% \mathrm{CI}, 1.01-6.23)$, and with previous use of multiple concentrates $(\mathrm{OR}=4.94 ; 95 \% \mathrm{CI}, 1.59-15.39)$. F8 mutation type - i.e., the specific form of $F 8$ null mutation - was not associated with inhibitor development. The unadjusted OR for being inhibitor positive when IDO1 incompetent was 4.57 (95\% CI, 1.96-10.64), rising to 8.11 (95\% CI, 1.05-62.41) when adjusted for family history of anti-FVIII antibodies, previous treatment with plasma-derived or recombinant FVIII, and previous use of single (i.e., the consistent use of the same FVIII product) or multiple concentrates (i.e., on switching/alternating different FVIII products). The unadjusted OR of having cleared a previous inhibitor, either spontaneously or by ITI, when IDO-competent versus incompetent was 3.0 (95\% CI, 0.91-9.92). The corresponding adjusted OR was 2.37 (95\% CI, 0.18-31.40). The ordinal logistic model for the association between having a previous (or current) positive inhibitor status or being consistently inhibitor negative and the lack of IDO1 versus IDO1 competence allowed for an estimated unadjusted OR of 4.86 (95\% CI, 2.17-10.87). When adjusted for family history of inhibitors, previous treatment with plasma-derived or recombinant FVIII, and previous use of single or multiple concentrates, the OR was 4.01 (95\% CI, 1.19-13.51).

The relative contributions of the main PBMC subsets to IDO1 expression and activity were investigated, demonstrating no upregulation in B cells (Figure 1E), as opposed to what was found in unfractionated DCs (Figure 1F), with comparable IDO1 upregulation in plasmacytoid DCs, myeloid DCs, and monocytes (Supplemental Figure 1). No statistically significant differences in TLR9 mRNA and TLR9 protein expressions were found between inhibitor-positive and -negative patients (Supplemental Figure 2). On examining the most common genetic variants affecting TLR9 function, we found that the genotype frequencies of TLR 9 singlenucleotide polymorphisms did not differ between the 2 groups of patients (Supplemental Table 3).

Stimulation of PBMCs from inhibitor-free patients with CpGODN resulted in significant increases in immunoregulatory cytokines (namely, TGF- $\beta 1,-2$ and -3), whereas stimulation of cultured cells from inhibitor-positive patients did not. Conversely, the production of proinflammatory cytokines (i.e., IL-12, IL-1, and IL-6) was significantly higher in PBMCs from inhibitor-positive patients after stimulation (Figure $1 \mathrm{G}$ and Supplemental Figure 3). Interestingly, PBMCs from the 2 groups of patients produced similar amounts of IFN- $\gamma$-induced protein 10 (IP-10) and IFN- $\alpha$ after stimulation with CpG-ODN (Figure 1G). Likewise, other cytokines, such as IL-4, IL-17, and IFN- $\gamma$, were not differentially expressed by the 2 groups (Supplemental Figure 3). Because IP-10 and IFN- $\alpha$ might contribute to IDO1 induction in monocytes and in conventional DCs - which express relatively low levels of TLR9 - we analyzed CpG-mediated induction of IP-10 and IFN- $\alpha$ in plasmacytoid DCs, monocytes, and myeloid DCs (Supplemental Figure 4, A and B). We also determined IDO1 expression in monocytes and myeloid DCs in the presence or absence of neutralizing antibodies to IP-10 and IFN- $\alpha$ (Supplemental Figure 4C). IP-10 was produced by monocytes and myeloid DCs, and to an even greater extent by plasmacytoid DCs. In contrast, IFN- $\alpha$ was poorly (plasmacytoid DCs and monocytes) or not at all (myeloid DCs) induced by CpG-ODN stimulation. We also found that combined neutralization of both cytokines in myeloid DCs or monocytes opposed - yet, did not ablate - IDO1 induction by CpG-ODN (Supplemental Figure 4C). This implies that additional factors may indirectly contribute to IDO1 expression in those cells stimulated with CPG-ODN. (TGF- $\beta$ might well be one such candidate.) We found no evidence for direct stimulation of highly purified human monocytes by CpG-ODN.

Thus, in a cohort of 100 severe hemophilia A patients, with and without inhibitors - but with $F 8$ mutations resulting in complete absence of endogenous FVIII - there occurred a strong and statistically significant association between failure to activate IDO1 in response to CpG-ODN and the presence of inhibitors.

TLR9 stimulation prevents inhibitors in hemophilic mice through IDO1 induction. To experimentally examine any role for IDO1 in restraining anti-FVIII responses, we crossed $\mathrm{F}^{-/-}$(hemophilic) with $I \mathrm{do1}^{-/-}$mice, thus generating an FVIII- and IDO1-deficient phenotype. CpG-ODN immunoregulatory effects in mice are strictly dependent on dosage (22). FVIII KO as well as FVIII and IDO1 double-KO (DKO) mice were immunized with recombinant human FVIII (rhFVIII) (0.2 $\mu$ g weekly; for 4 weeks) either alone or in combination with low-dosage $\left(1 \mu \mathrm{g} ; \mathrm{CpG}_{\mathrm{L}}\right)$ or high-dosage $\left(50 \mu \mathrm{g} ; \mathrm{CpG}_{\mathrm{H}}\right)$ CpG-ODN administered over the first 3 weeks of immunization (Figure 2A). Treatment of immunized, FVIII-deficient mice with $\mathrm{CpG}_{\mathrm{H}}$, but not $\mathrm{CpG}_{\mathrm{L}}$, prevented FVIII-specific antibody production in IDO1-competent but not DKO mice (Figure $2 \mathrm{~B}$ ). This effect required that $\mathrm{CpG}-\mathrm{ODN}$ be administered 24 

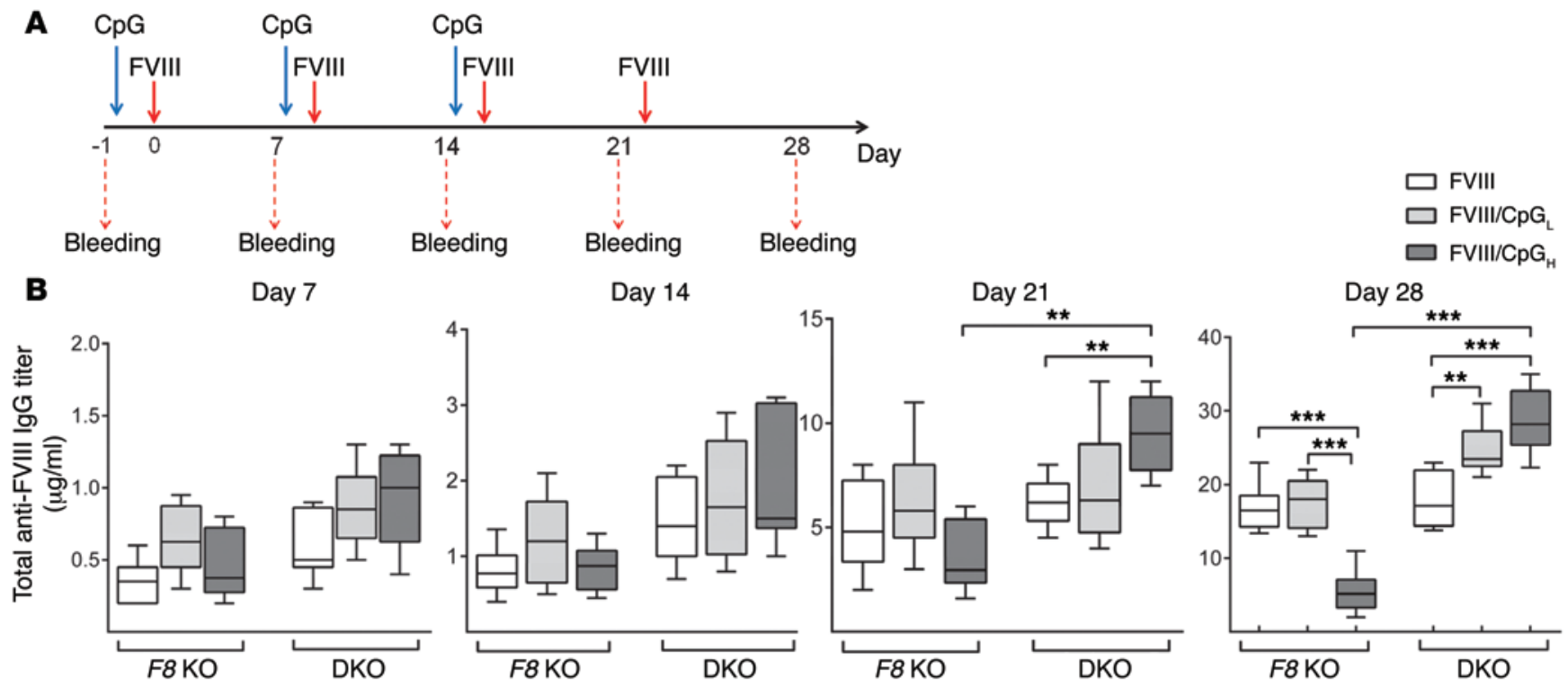

C
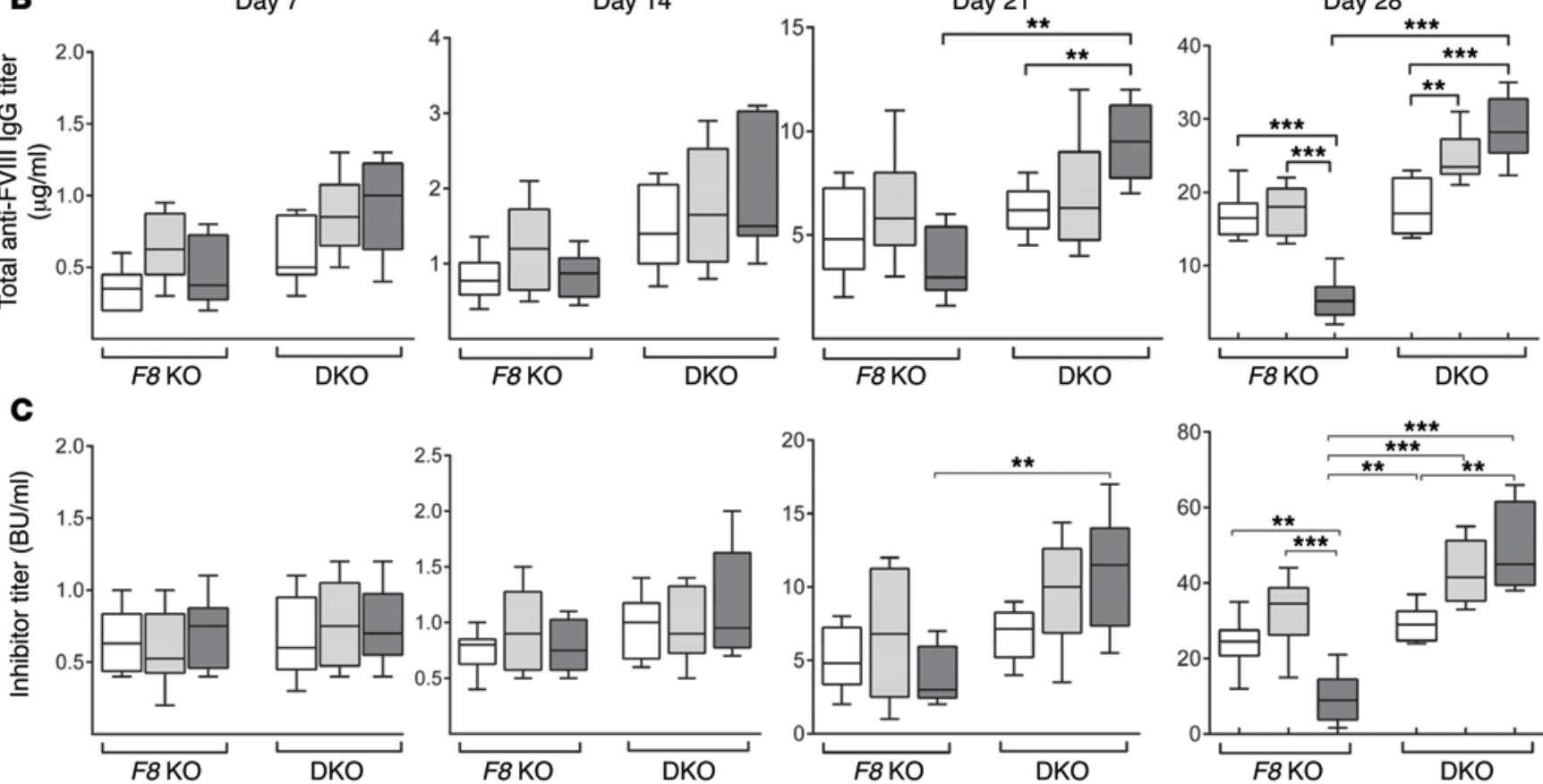

Figure 2. $\mathrm{CpG}_{H}$ suppresses anti-FVIII antibody production via IDO1 in hemophilic mice. (A) Treatment regimen: $F 8 \mathrm{KO}$ and DKO mice $(n=8)$ received intravenous rhFVIII (200 ng weekly). In the first 3 weeks, $\mathrm{CpG}_{H}, \mathrm{CpG}_{\mathrm{L}}$, or vehicle (PBS) was given 24 hours before FVIII administration. (B) The anti-FVIII antibody response was measured in both genotypes. (C) Neutralizing antibody titers were measured and expressed as BU. Vertical middle lines represent the first and the third quartiles, and horizontal lines indicate the median values (with whiskers being minimum and maximum values). Three independent experiments are shown. ${ }^{* *} P<0.01 ;{ }^{* *} P<0.001$, ANOVA followed by Bonferroni's correction.

hours prior to FVIII because simultaneous administration of $\mathrm{CpG}$ and FVIII or administration of CpG after FVIII would instead lead to a strong increase in antibody titers (Supplemental Figure 5). In contrast, both $\mathrm{CpG}_{\mathrm{H}}(P=0.0008 ; \mathrm{CpG}$ versus vehicle $)$ and $\mathrm{CpG}_{\mathrm{L}}$ $(P=0.002 ; \mathrm{CpG}$ versus vehicle) increased the antibody response in the DKO mice (Figure 2B). Consistent results were obtained in a functional assay, namely, the Bethesda assay, which measures the actual neutralizing ability of anti-FVIII antibodies (Figure 2C). Total IgG titers were similar in the 2 genotypes before (day 0 ) and after treatment (on day 28 after immunization), with no significant differences among groups (Supplemental Figure 6).

We characterized the immunoglobulin isotypes of the antibody response to rhFVIII in mice of either genotype. On administering rhFVIII alone, the levels of FVIII-specific IgM and IgG $_{1}$ were higher in DKO mice as compared with $\mathrm{F}^{-/-}$mice on days 14 and 28 after immunization. Similar isotype ratios were observed on combining rhFVIII immunization with $\mathrm{CpG}_{\mathrm{L}}$, although all Ig subclasses were expressed at higher levels than in response to rhFVIII alone. $\mathrm{CpG}_{\mathrm{H}}$ prevented the development of rhFVIII-specific IgG $\mathrm{G}_{1}$ and $\mathrm{IgG}_{3}$ in IDO1-competent mice, yet treatment increased antibody production in the DKO mice at day 28 after immunization (Figure
3A). These data demonstrated that, regardless of its dosage, CpGODN enhances anti-FVIII antibody production in IDO1-deficient hemophilic mice, whereas $\mathrm{CPG}_{\mathrm{H}}$ selectively prevents FVIII-specific antibody formation in IDO1-competent, FVIII KO mice.

Consistent with this, ELISpot analysis showed that $\mathrm{CPG}_{\mathrm{H}}$, but not $\mathrm{CpG}_{\mathrm{L}}$, dramatically reduced the number of FVIII-specific antibody-secreting cells in IDO1-competent hemophilic mice at 28 days of immunization, in contrast to what was observed in DKO mice, in which either CpG-ODN treatment regimen increased the number of FVIII-specific antibody-secreting cells (Figure 3, B and C).

Tryptophan metabolites prevent generation of anti-FVIII antibodies in hemophilic mice. We investigated the role of CpG-ODN administration in vivo in conditioning IDO1 expression in FVIIIdeficient mice. As expected, treatment with $\mathrm{CpG}_{\mathrm{H}}$, but not $\mathrm{CpG}_{\mathrm{L}}$, increased Ido1 transcript (Figure $4 \mathrm{~A}$ ) and protein expressions (Figure $4 \mathrm{~B}$ ) in the spleens of FVIII KO mice. Immunofluorescent staining revealed that $\mathrm{CpG}_{\mathrm{H}}$, but not $\mathrm{CpG}_{\mathrm{L}}$, favored IDO1 expression in splenic CD11 $\mathrm{c}^{+}$cells, usually referred to as classical DCs (Figure $4 \mathrm{C}$ ). These $\mathrm{IDO}^{+}$cells were mostly expressed in the inner region of periarteriolar sheaths (PALS) and, to a lesser extent, in the marginal zones (Supplemental Figure 7). We measured kynurenine- 
A

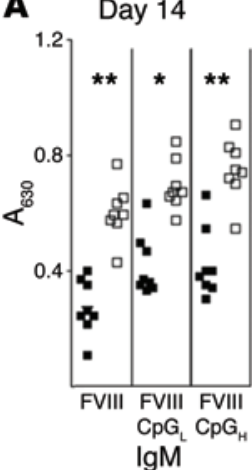

$\lg \mathrm{M}$

Day 28

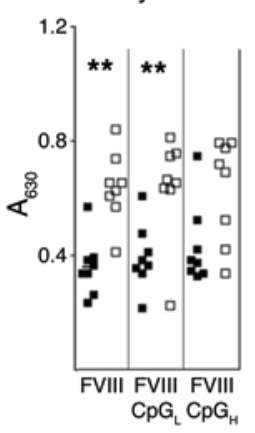

$\lg M$

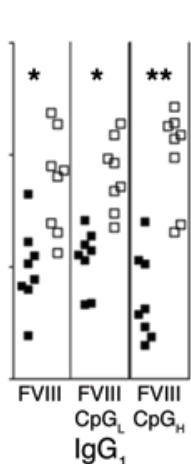

$\lg G_{1}$

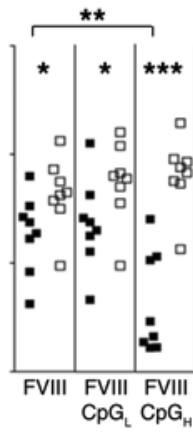

$\lg G_{1}$
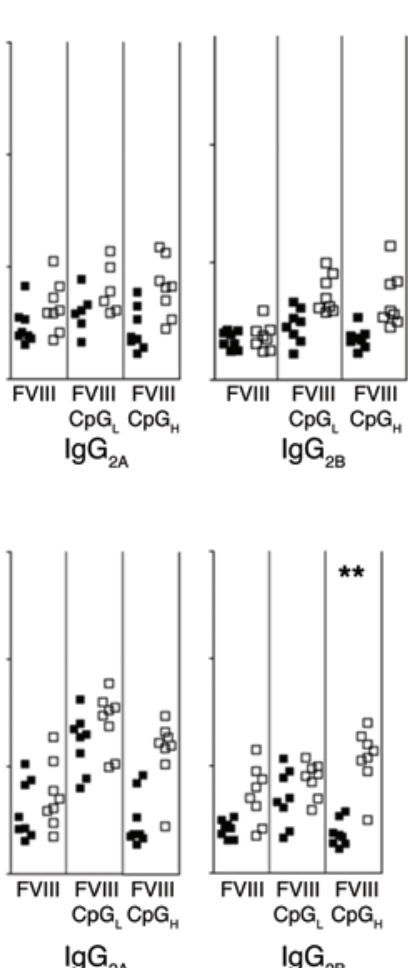

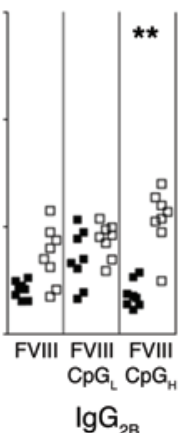

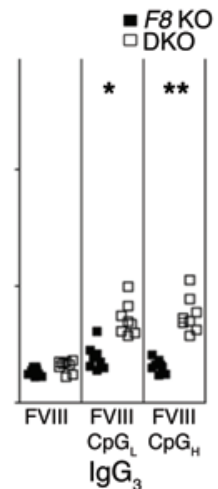

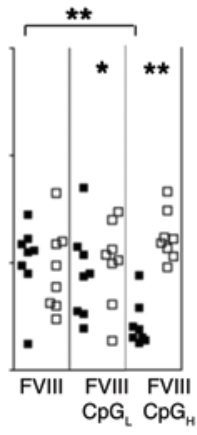

$\operatorname{lgG}_{3}$
B

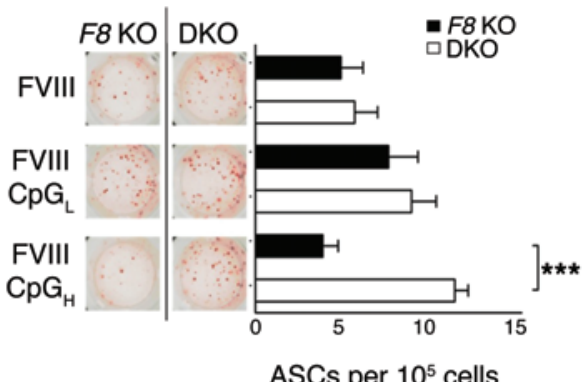

C

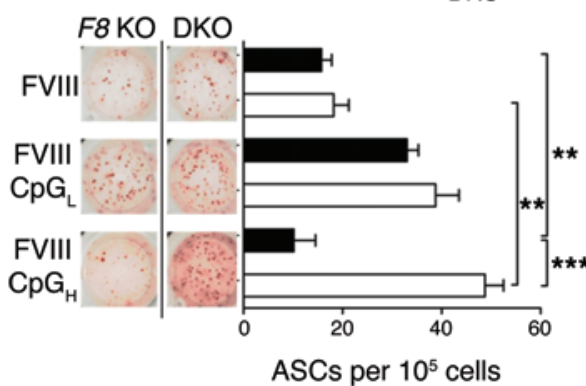

Figure 3. CpGH reduces humoral anti-FVIII immune response in ID01-competent hemophilic mice. (A) Serum anti-FVIII IgG isotype levels in mice treated as in Figure 2A were measured by ELISA on days 14 and 28. FVIII-specific IgG-secreting plasma cells were enumerated by ELISpot in the spleens of $F 8$ KO and DKO mice on days 14 (B) and 28 (C). In B and C, data are from 2 independent experiments ( $n=8$ per group per experiment), with representative ELISpot images (1 out of 3 samples) for an individual mouse per genotype per treatment. In all panels, data represent mean \pm SD. ${ }^{*} P<0.05$; ${ }^{* *} P<0.01$; ${ }^{* *} P<0.001$, ANOVA followed by Bonferroni's multiple comparison test. ASCs, antibody-secreting cells.

to-tryptophan (kyn/trp) ratio - an indicator of IDO1 enzymic function - in sera from FVIII KO and DKO mice treated with FVIII either alone or in combination with $\mathrm{CpG}_{\mathrm{L}}$ or $\mathrm{CpG}_{\mathrm{H}}$ (Figure 2A). We found a significant increase in kyn/trp ratios in FVIII KO mice when treated with $\mathrm{CpG}_{\mathrm{H}}$, but not with $\mathrm{CpG}_{\mathrm{L}}$. In DKO mice, no changes in kyn/trp ratios were observed (Figure 4D). Administration of 1-methyl-tryptophan (1-MT), a competitive inhibitor of IDO1, reversed the protective effect of $\mathrm{CpG}_{\mathrm{H}}$ to a significant extent on day 28 after immunization (Supplemental Figure 8).

The mechanisms of IDO1 in promoting regulatory effects include the production of immunoactive tryptophan catabolites, of which L-kynurenine, an amino acid itself, is the first byproduct in the kynurenine pathway of tryptophan degradation (23). The immunoactive properties of L-kynurenine include engagement of the aryl hydrocarbon receptor (AhR) in DCs to promote T cell regulatory activity in response to deregulated TLR signaling (24) and in adaptive immunity as well $(23,25)$. We investigated the effect of L-kynurenine administration on inhibitor production in FVIII KO and DKO mice immunized for 4 weeks with rhFVIII. Oral treatment with L-kynurenine $(5 \mathrm{mg} /$ mouse; 3 times weekly, for 3 weeks and concomitantly with FVIII) prevented inhibitor production in FVIII KO mice. The protective effect was comparable to that obtained by $\mathrm{CpG}_{\mathrm{H}}$ administration in IDO1-competent hemophilic mice. Of note, the protective effect of supplemental L-kynurenine was negated by coadministration of the AhR antagonist $\mathrm{CH}-223191$ (Figure 4E). Overall, these results confirmed the crucial role of
$\mathrm{CpG}_{\mathrm{H}}$-induced, IDO1-dependent tryptophan catabolism in preventing FVIII-specific antibody production in hemophilic mice.

$C p G_{H}$ restricts inflammatory cytokines in IDO1-competent hemophilic mice. Flexibility in FVIII presentation by DCs mostly reflects autocrine effects by a set of cytokines that either reinforce or subvert a default presentation profile $(26,27)$. To determine whether $\mathrm{CpG}_{\mathrm{H}}$ treatment - concomitant with FVIII immunization - would differentially influence the patterns of cytokine secretion in FVIII KO and DKO mice, we measured circulating cytokine titers by a multiplex cytokine assay. Fold changes in cytokine titers (i.e., ratios of measurements at 3, 24, and 48 hours of each FVIII immunization to preimmunization values) were recorded and graphically represented as a heat map (Figure 5A). In addition, the absolute values $(\mathrm{pg} / \mathrm{ml})$ of those cytokines with a fold difference of more than 2 between the 2 genotypes on at least 1 occasion were recorded (Figure 5, $\mathrm{B}-\mathrm{G})$. In FVIII KO mice, but not in their DKO counterparts, the inflammatory cytokine response to $\mathrm{CpG}$ gradually decreased over the course of repeated $\mathrm{CpG}$ injections, whereas TGF- $\beta$ increased. Specifically, $\mathrm{CpG}_{\mathrm{H}}$ increased IL- 6 production only in the first 2 weeks of immunization in FVIII KO mice, yet it sustained IL-6 production throughout the observation period in the DKO mice (Figure 5B). This suggested that IDO1 is necessary for downregulating IL- 6 on repeated exposure of hemophilic mice to exogenous FVIII. Much like the effect on inhibitor formation (Figure $2 \mathrm{~B}$ ), $\mathrm{CpG}_{\mathrm{H}}$ restrained inflammatory cytokine produc- 

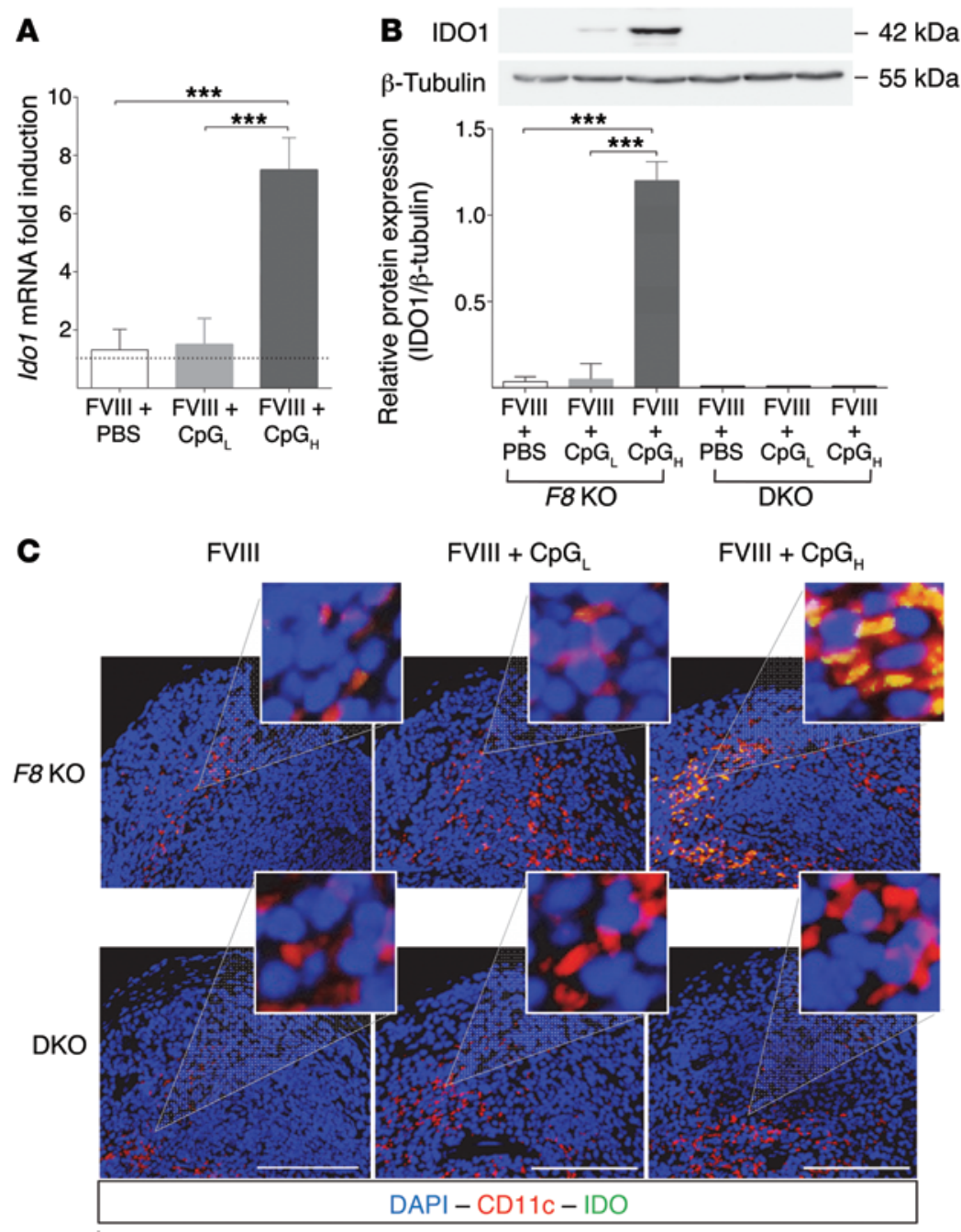
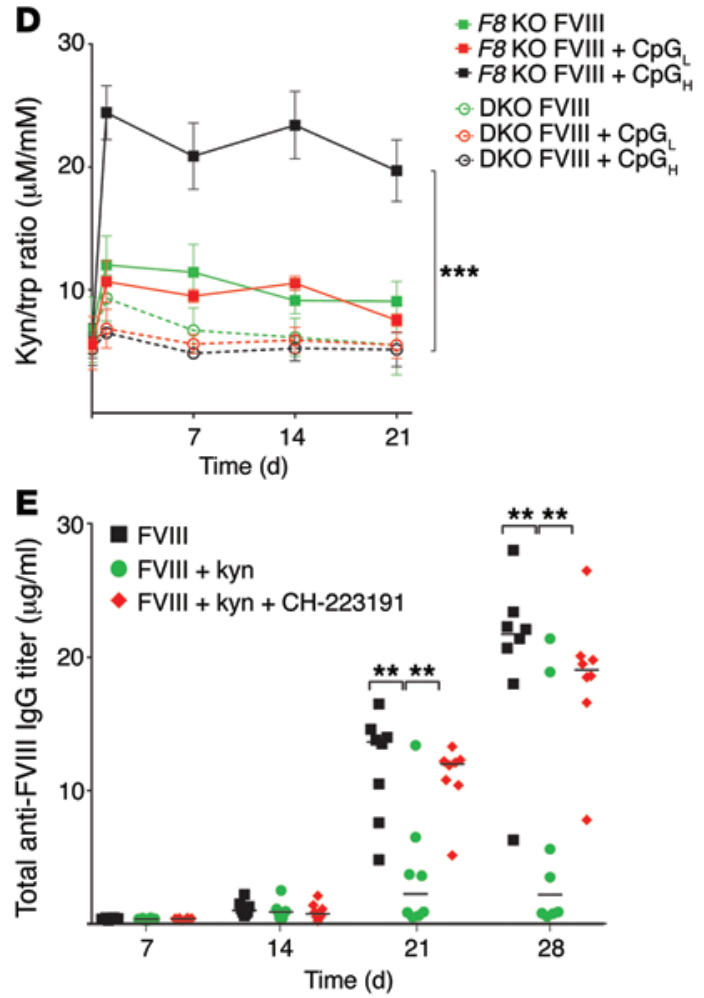

Figure 4. $\mathrm{CpG}_{\mathrm{H}}$ promotes protective IDO1 expression and activity in F8 KO mice. (A) Ido1 transcript expression in total splenocytes from F8 KO mice, pretreated with $\mathrm{CpG}_{\mathrm{H}}, \mathrm{CpG}_{\mathrm{L}}$, or PBS (control), at 14 days of treatment. Data (mean $\pm \mathrm{SD}$ ) are presented as normalized transcript expression in the samples relative to normalized transcript expression in control splenocytes (that is, cells from vehicle-treated mice, in which fold change $=1$; dotted line) in 1 experiment representative of 2. (B) Immunoblot analysis of IDO1 protein in total splenocytes from F8 KO and DKO mice treated as in A. One experiment is representative of 3. IDO1/ $\beta$-tubulin ratios, underneath immunoblotting, are mean \pm SD from 3 experiments. (C) Splenic immunofluorescent staining. Scale bars: $100 \mu \mathrm{m}$. (D) kyn/trp ratios in sera from mice treated as in $\mathbf{A}$ (mean \pm SD of 3 experiments). $n=8$. (E) Anti-FVIII humoral immune response of variously treated mice; $n=8$. ${ }^{* *} P<0.01 ;{ }^{* *} P<0.001$, ANOVA followed by Bonferroni's correction.

tion only in the singly KO mice, with IDO1 deficiency resulting instead in increased cytokine production.

IDO1 is necessary for sustained TGF- $\beta$ production (12). In our setting, $\mathrm{CpG}_{\mathrm{H}}$ induced TGF- $\beta$ production in both genotypes, yet the cytokine rapidly declined in the DKO mice, in marked contrast with the steadily increasing production in the singly KO hemophilic mice. Although anti-TGF- $\beta$ would not abolish the inhibitor-opposing effect of $\mathrm{CpG}_{\mathrm{H}}$ in the latter mice, there was a trend toward increased anti-FVIII antibody titers, which was consistent with a role for TGF- $\beta$ and IL-10 in inhibiting anti-FVIII antibody responses in FVIII KO mice (28). Much like anti-TGF- $\beta$, anti-IL-10 alone was ineffective in reverting $\mathrm{CpG}_{\mathrm{H}}$ effects, yet a combination of the 2 antibodies did so, restoring FVIII-specific humoral responses (Supplemental Figure 9). Although ratios of measured values for circulating IL-10 in KO to DKO mice were less than 2, IL-10 was, indeed, significantly higher $(P=0.009$; at 3 hours of week 2; $P=0.008$; at 3 hours of week 3 ) in FVIII KO than in DKO mice treated with $\mathrm{CpG}_{\mathrm{H}}$ (Figure $4 \mathrm{~A}$ ). Although we did not detect an increase in circulating IL-17A, consistent with previous studies in C57BL/6 mice, we found an increase in $I l 17 a$ and in Rorc and a reduction in Foxp 3 transcripts in the $\mathrm{CD} 4^{+} \mathrm{T}$ cells from hemophilic IDO1 KO mice treated with $\mathrm{CpG}_{\mathrm{H}}$, whereas the same treatment resulted in increased Foxp3 and decreased Il17a expressions in IDO1-competent hemophilic mice (Supplemental Figure 10).

Moreover, in experiments not reported here, we found that $\mathrm{CpG}_{\mathrm{H}}$ increased $\mathrm{CD} 25^{+} \mathrm{CD} 4^{+} \mathrm{Foxp}^{+}$Tregs in FVIII KO mice but not DKO mice. Thus, both TGF- $\beta$ and IL-10 contribute - via IDO1 - to inhibitor and proinflammatory cytokine suppression by $\mathrm{CpG}_{\mathrm{H}}$ in hemophilic mice.

Suppression of FVIII-specific B cells by $C p G_{H}$ requires IDO1. Germinal centers (GCs) are lymphoid microenvironments that are formed at the height of an ongoing immune response and are criti- 

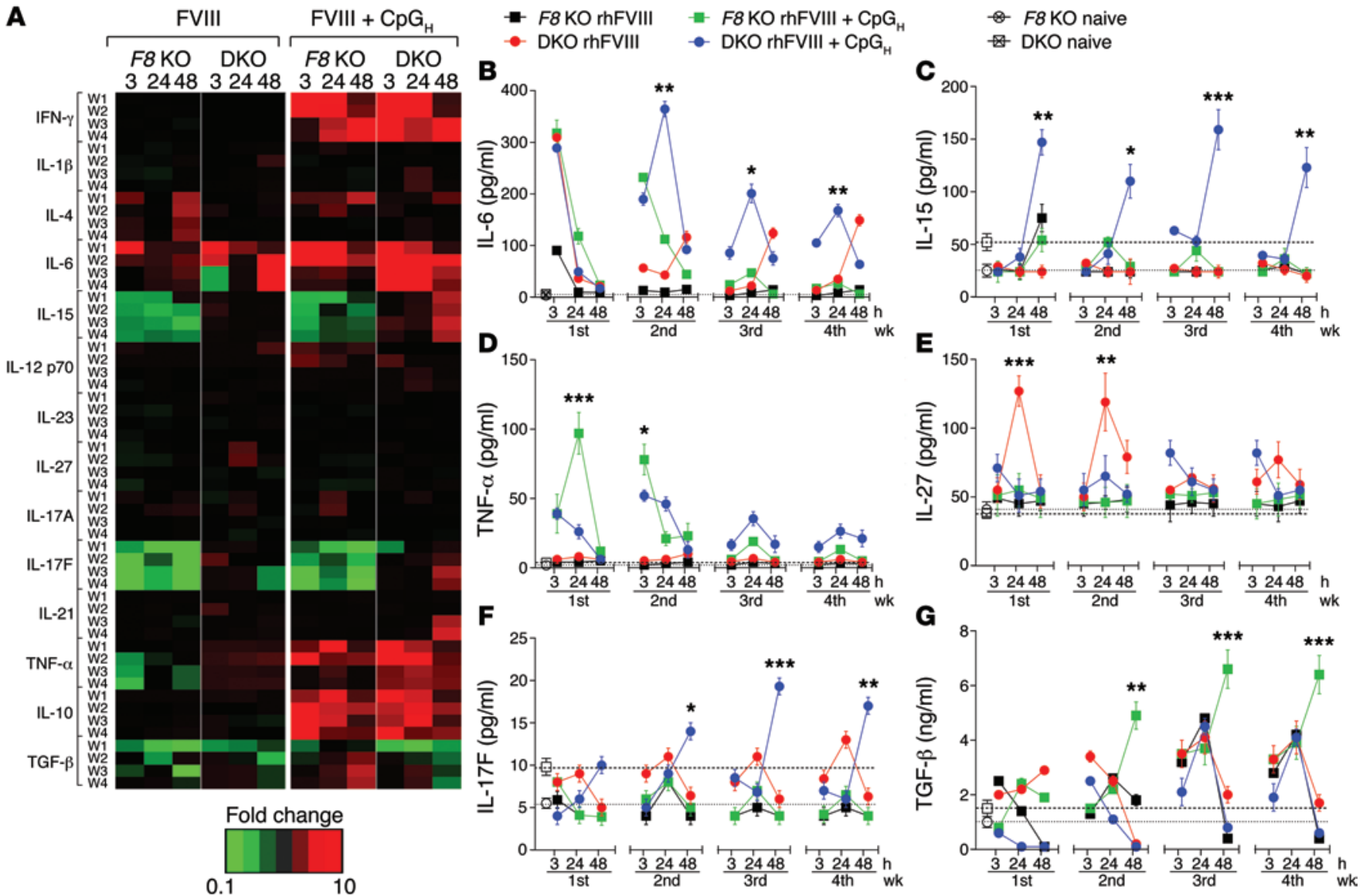

Figure 5. $\mathrm{CPG}_{\mathrm{H}}$ promotes production of antiinflammatory cytokines and suppresses proinflammatory cytokines in the sera from $F 8 \mathrm{KO}$ mice. (A) Heat map representation of plasma cytokine responses in mice treated as in Figure 2A. Data (mean \pm SD of 3 experiments) are presented as fold change in cytokine concentrations at each time point over the respective, untreated genotype-matched control. (B-G) Levels of cytokines with fold increases greater than 2 are reported. Data represent mean \pm SD from 3 experiments; $n=6$ per group per experiment. Dashed and dotted lines represent basal plasma cytokine levels in untreated F8 KO and DKO mice, respectively. ${ }^{*} P<0.05 ;{ }^{* *} P<0.01$; ${ }^{* *} P<0.001$, ANOVA followed by Bonferroni's multiple comparison test.

cal for optimizing T cell-dependent humoral immune responses $(29,30)$. During GC reactions, activated B cells undergo antigendriven changes, such as Ig heavy-chain class switching and affinity maturation, ultimately leading to the generation of memory B- and antibody-producing plasma cells. Because serum titers of the high-affinity isotypes specific for FVIII were most dramatically affected by $\mathrm{CpG}_{\mathrm{H}}$, we evaluated the formation of GC in FVIII $\mathrm{KO}$ and DKO mice immunized with rhFVIII alone or in combination with $\mathrm{CpG}_{\mathrm{H}}$. Specifically, to determine whether $\mathrm{CpG}_{\mathrm{H}}$ affected humoral FVIII-specific responses - thus resulting in changes in GC formation - we stained spleen cells from immunized mice with biotin-labeled peanut agglutinin (PNA), a lectin known to specifically bind GC cells. Weekly treatments with $\mathrm{CpG}_{\mathrm{H}}$ did not produce obvious changes on gross spleen histopathology. At 7 days after a second exposure to rhFVIII, B cell follicles were present in hemophilic and, to a greater extent, in DKO mice treated with rhFVIII alone. (The difference was not, however, statistically significant; $P=0.063$.) Coadministration of $\mathrm{CpG}_{\mathrm{H}}$ to hemophilic but IDO1-competent mice significantly suppressed GC formation, which was instead markedly enhanced in the DKO mice (Figure 6A). Enumeration of GC size distributions in the 2 genotypes revealed a significantly higher distribution in the DKO mice, particularly when treated with $\mathrm{CpG}_{\mathrm{H}}$, as compared with FVIII KO $(P<0.0001)$ (Figure 6B). FACS analysis of splenic B cell subsets confirmed a reduction in activated $\mathrm{B}$ cells $\left(\mathrm{CD} 19^{+} \mathrm{Gl} 7^{+}\right)$as well as plasma cells $\left(\mathrm{CD}^{2} 9^{+} \mathrm{CD} 138^{+}\right)$in FVIII KO mice treated with $\mathrm{CpG}_{\mathrm{H}}$, and the opposite held true for the DKO mice (Supplemental Figure 11). In accordance with these data, the number of FVIII-specific antibody-secreting cells was increased in DKO mice receiving $\mathrm{CpG}_{\mathrm{H}}$, as opposed to what was observed in FVIII KO mice (Figure 5C). Analysis of $B$ cell transcription factors demonstrated that $\mathrm{CpG}_{\mathrm{H}}$ would enhance expression of Bcl-6 and Pax 5 - inversely related to B cell differentiation - selectively in IDO1-competent mice. Treatment did not affect the expression of 2 other B cell transcription factors (XBP-1 and Prdm1) - critical for terminal differentiation of B cells into plasma cells - in either genotype (Figure 6D). Overall, these results suggested that pretreatment with $\mathrm{CpG}_{\mathrm{H}}$ before rhFVIII administration opposes FVIII-specific antibody production in hemophilic mice and that the effect is strictly dependent on IDO1 function.

Ectopic IDO1 expression in DCs from inhibitor-positive patients restores FVIII-specific Treg responses. NF- $\mathrm{KB}$ is a constitutive transcription factor, with a strong presence in DCs, where it mediates both inflammatory and antiinflammatory functions (31). Molecu- 

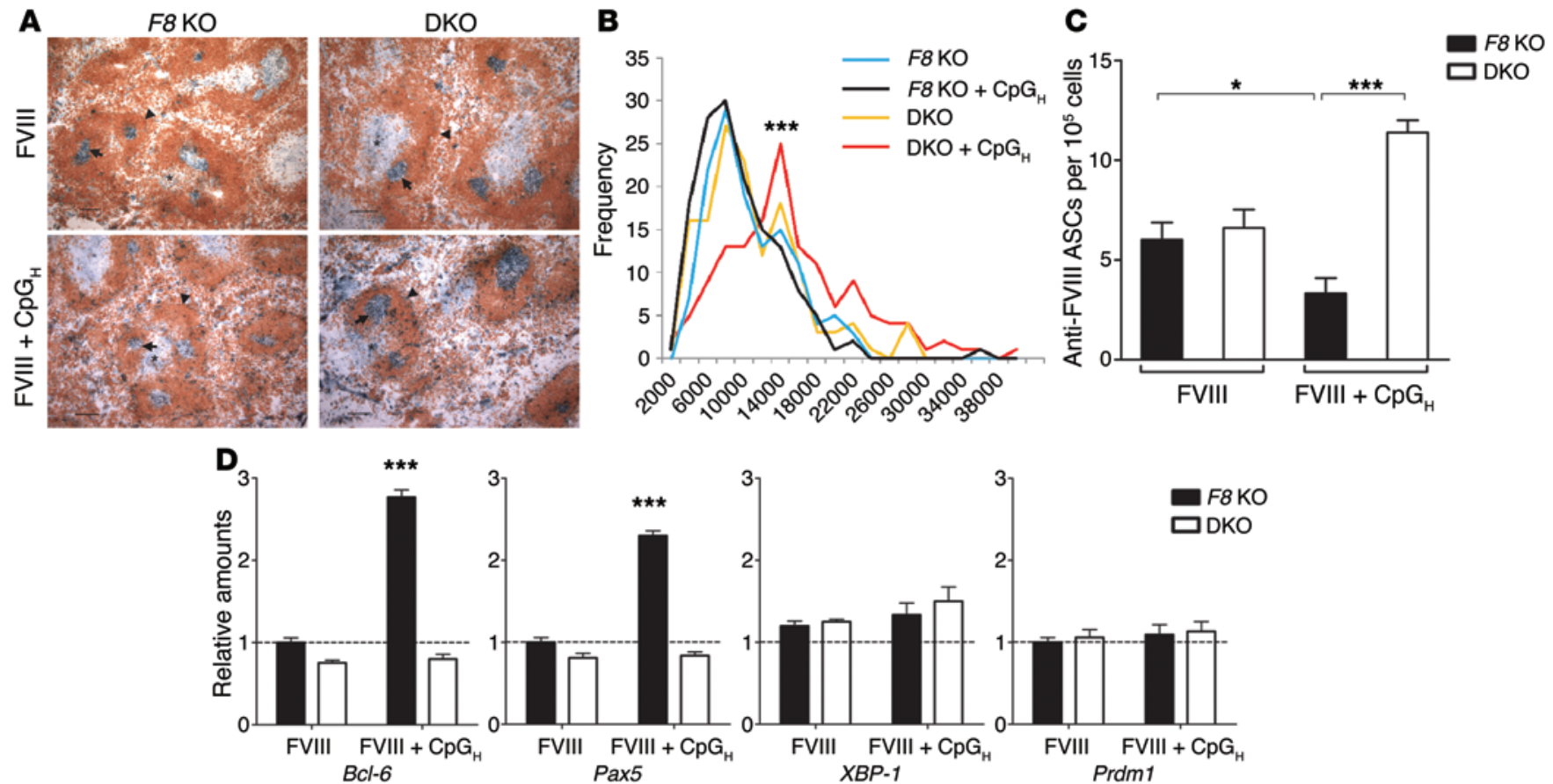

Figure 6. $\mathrm{CpG}_{\mathrm{H}}$ favors FVIII-specific B cell differentiation into plasma cells in DKO but not $\mathbf{F 8} \mathrm{KO}$ mice. (A) GC immunohistochemistry in spleens from F8 $\mathrm{KO}$ and DKO mice treated with FVIII, alone or in combination with $\mathrm{CpG}_{\mathrm{H}}$, as in Figure $2 \mathrm{~A}$, on day 18 of treatment. Original magnification, $\times 20$. Arrows indicate $\mathrm{GCs}$, arrowheads the outer edge of follicles, and asterisks the central artery in the T cell zone. Representative results from 1 of 3 experiments;

$n=5$. (B) Frequency distribution of GC areas in 1 of 3 experiments. In 5 consecutive sections, cut from 4 sectioning planes $250 \mu \mathrm{m}$ apart, at least 120 GC areas were analyzed in each spleen. Data are for 6 to 8 complete GCs from 3 mice per genotype per treatment group. (C) Number of anti-FVIII IgG-secreting plasma cells, assessed by ELISpot, in the spleens of F8 KO and DKO mice, treated as in A (day 18). In B and C, data represent mean \pm SD of 3 experiments; $n=6$ per group per experiment. ${ }^{*} P<0.05$; ${ }^{* *} P<0.001$, ANOVA followed by Bonferroni's multiple comparison test. (D) B cell gene transcript expression in $G L 7^{+} B$ cells on day 18. Data (mean \pm SD of 3 experiments; $n=5$ per group per experiment) are presented as normalized transcript expression in the samples relative to normalized transcript expression in control naive B cells (in which fold change $=1$; dotted line). ${ }^{* * *} P<0.001$, 2 -tailed Student's $t$ test.

lar dissection of NF-kB activation has shown that NF-kB can be induced by the so-called canonical and noncanonical signaling pathways, leading to distinct patterns in the individual NF-KB subunits that are activated and downstream genetic responses (32, 33). IDO1 expression is contingent on the noncanonical pathway of NF- $\mathrm{KB}$ activation (34), and the Ido1 promoter contains putative noncanonical NF- $\mathrm{kB}$-binding sites recognized by noncanonical p52/RelB dimers $(35,36)$. We have previously found that human Flt3L-derived DCs (FL-DCs) treated with $\mathrm{CpG}_{\mathrm{H}}(3 \mu \mathrm{g} / \mathrm{ml})$, but not $\mathrm{CpG}_{\mathrm{L}}(0.3 \mu \mathrm{g} / \mathrm{ml})$, show high-level noncanonical NF-кB activation, leading to IDO1 expression (22). We investigated the NF- $\mathrm{KB}$ activation patterns induced by $\mathrm{CpG}_{\mathrm{H}}$ in FL-DCs from hemophilic patients, with or without inhibitors, both receiving therapeutic FVIII. By ELISA assessment of the relative amounts of canonical $\mathrm{p} 65$ and noncanonical $\mathrm{p} 52$ subunits, we found that $\mathrm{CpG}_{\mathrm{H}}$ promoted rapid p52 recruitment in inhibitor-negative patients (Figure 7A), resulting in $I D O 1$ transcript induction (Figure $7 \mathrm{~B}$ ) and enzymic activity (Figure 7C). In FL-DCs from inhibitor-positive patients, treatment instead activated the $\mathrm{p} 65$ subunit (Figure 7A), with no detectable IDO1 induction (Figure 7, B and C).

We treated FL-DCs with $\mathrm{CpG}_{\mathrm{H}}$ and established cocultures of autologous FL-DCs and $\mathrm{CD} 4^{+} \mathrm{T}$ cells isolated from inhibitor-positive $(n=5)$ or -negative $(n=5)$ patients in the presence or absence of rhFVIII to monitor antigen-specific Treg induction. FL-DCs unexposed to $\mathrm{CpG}$-ODN were used as a control. We found a signif- icant increase in FVIII-specific $\mathrm{CD} 4^{+} \mathrm{FOXP}^{+}$cells on coculturing CpG-conditioned FL-DCs from inhibitor-negative patients (Figure 7, D and E), but not in those from inhibitor-positive patients. Transfection of FL-DCs from inhibitor-negative patients with IDO1-specific siRNA abolished the $\mathrm{CpG}_{\mathrm{H}}$ effect on Treg induction (Supplemental Figure 12), pointing to a role for IDO1 in the expansion of $\mathrm{CD} 4^{+} \mathrm{FOXP}^{+}$cells. Analysis of Th cell transcription factors demonstrated that $\mathrm{CpG}_{\mathrm{H}}$ conditioning of FL-DCs from inhibitornegative patients resulted in an 8- to 10-fold increase in FOXP3 transcripts, with no detectable effect on other transcription factor (i.e., TBET, RORC, and GATA3) expression (Supplemental Figure 13). Cytokine measurements in culture supernatants showed that CpG-treated FL-DCs from inhibitor-negative but not -positive patients were characterized by higher TGF- $\beta$ and IL-10 titers. Proinflammatory IFN- $\gamma$ was instead increased in inhibitor-positive cultures (Figure 7F). Overall, these data suggest that defective IDO1 induction in DCs from inhibitor-positive patients contributes to impaired FVIII-specific Treg induction.

Next, we examined the effect of forced IDO1 expression in FL-DCs from inhibitor-positive patients. FL-DCs were transfected with either a control (mock) or IDO1-expressing vector. Transfection resulted in increased IDO1 transcript (Figure 8A) and protein expressions (Figure 8B). We established cocultures of autologous, IDO1-transfected FL-DCs and $\mathrm{CD} 4^{+} \mathrm{T}$ cells in the presence or absence of rhFVIII. IDO1 overexpression promoted a significant 
A

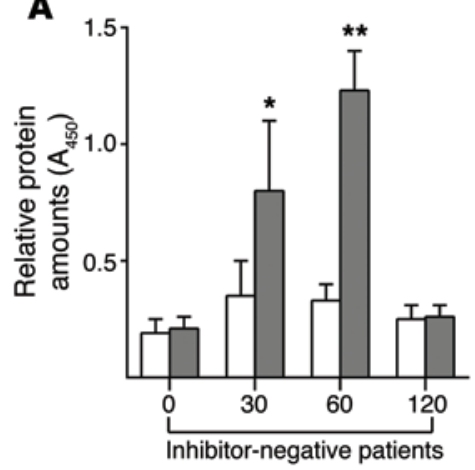

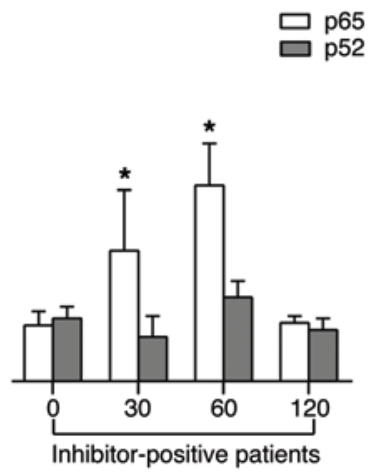

CpG ODN $2006 \longrightarrow$

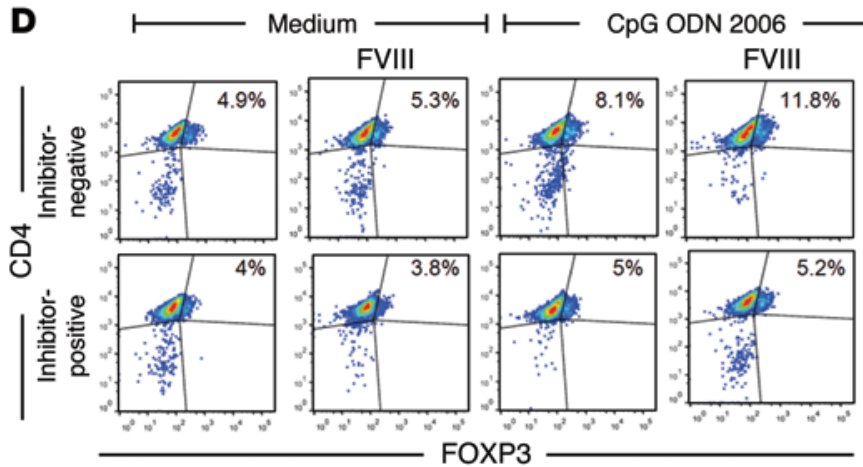

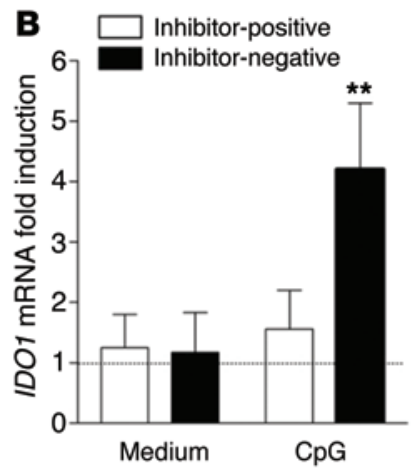

C

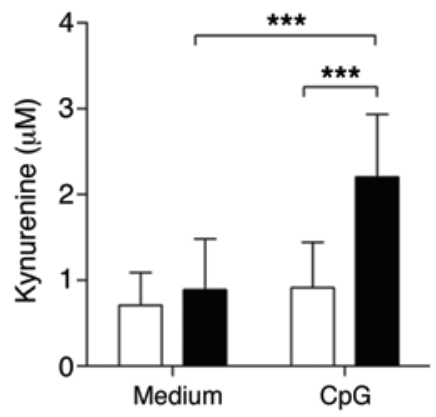

E
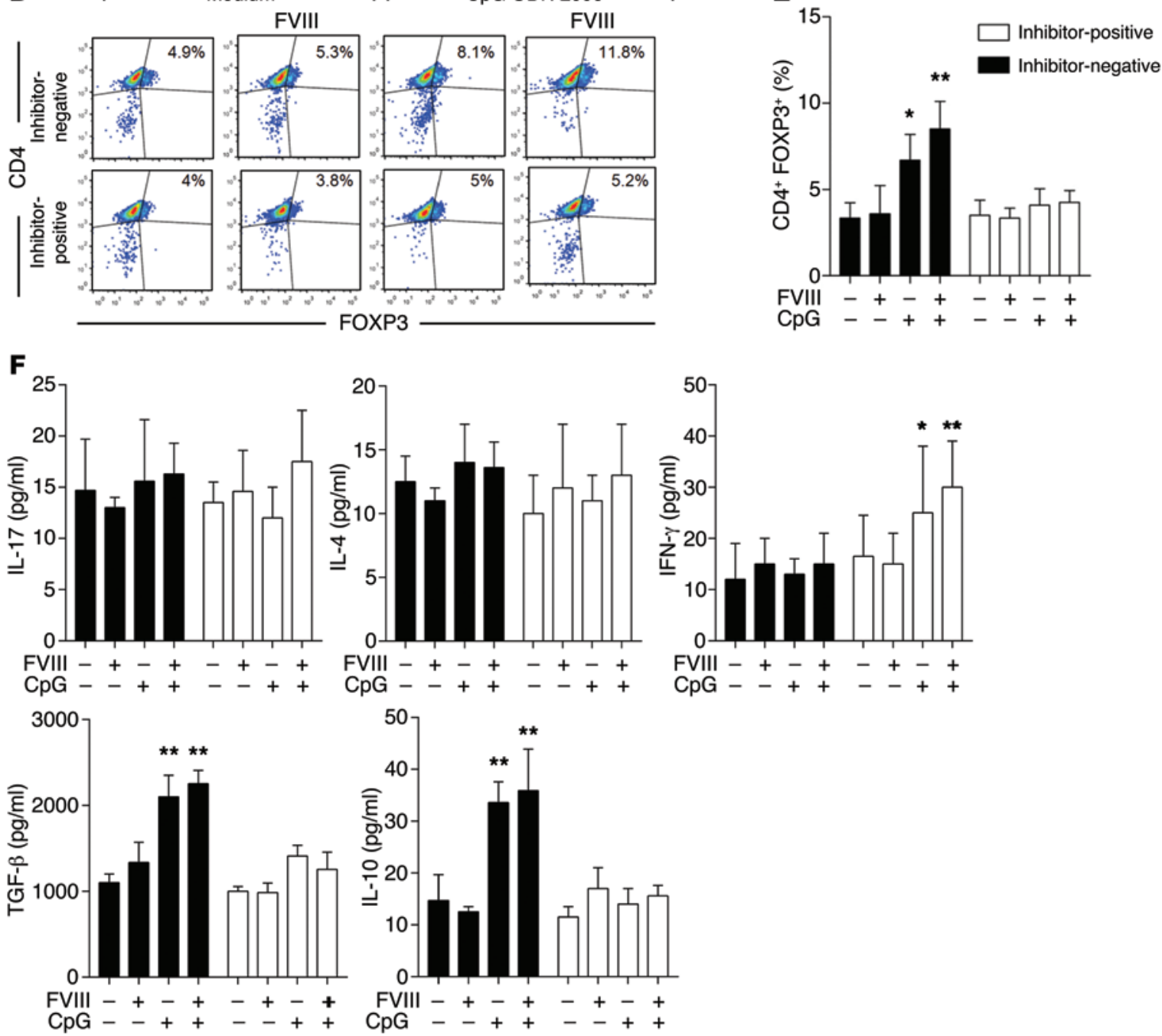

Figure 7. $\mathrm{CpG}_{\mathbf{H}} \mathbf{D C}$ treatment from inhibitor-negative patients promotes Treg responses. (A) ELISA measurements of the relative amounts $\left(\mathrm{A}_{450}\right)$ of $\mathrm{p} 65$ and 552 in DCs from inhibitor-negative and inhibitor-positive patients treated with CpG-ODN $(3 \mu \mathrm{g} / \mathrm{ml})$ at different times. Data represent mean \pm SD of 3 independent experiments. ${ }^{*} P<0.05$, Dunnett test (treatment vs. time 0 ). IDO1 transcripts (B) and L-kynurenine production (C) in FL-DCs from inhibitorpositive and inhibitor-negative patients, either untreated or treated with CpG-ODN ( $3 \mu \mathrm{g} / \mathrm{ml}) ; n=5$. IDO1 mRNA is presented relative to expression in the respective, freshly isolated DCs (in which fold change $=1$; dotted line). Data represent mean \pm SD of 3 experiments. ${ }^{* *} P<0.01$; ${ }^{* * *} P<0.001$, Student's $t$ test. (D) Representative results of $C D 4^{+} \mathrm{FOXP3}^{+}$cell frequency (top right quadrants) among CD4+ $\mathrm{T}$ cells, cultured for 5 days with $\mathrm{DCs}$, either untreated or $\mathrm{CpC}$ treated, with or without rhFVIII. Representative results from 1 experiment of 5 . (E) $C D 4^{+} \mathrm{FOXP3}^{+}$cell frequency in cultures established as in $\mathbf{D} ; n=5$. Mean \pm SD (3 independent experiments). (F) Cytokine analysis in cells treated as in $\mathbf{D}$ on day $4 .{ }^{*} P<0.05 ;{ }^{*} P<0.01$, Student's $t$ test. 
A

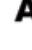

A

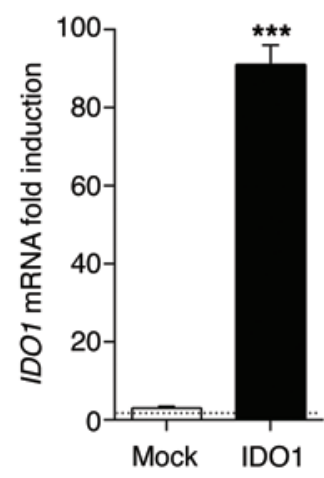

B
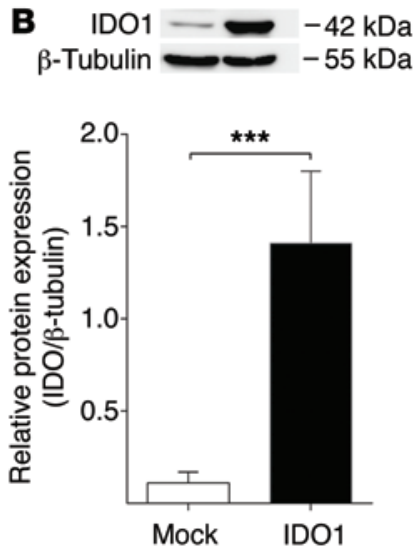

C

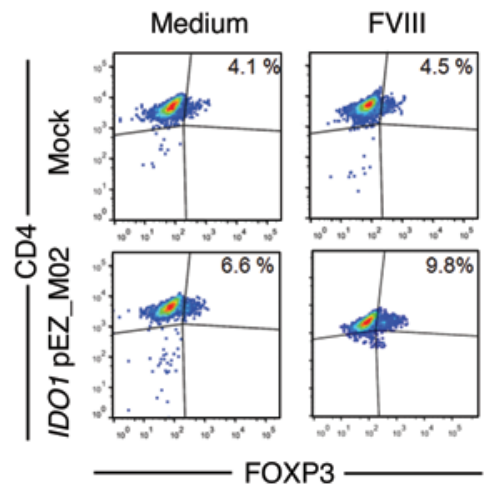

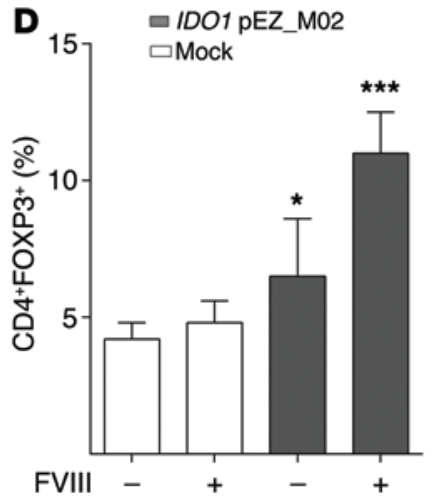

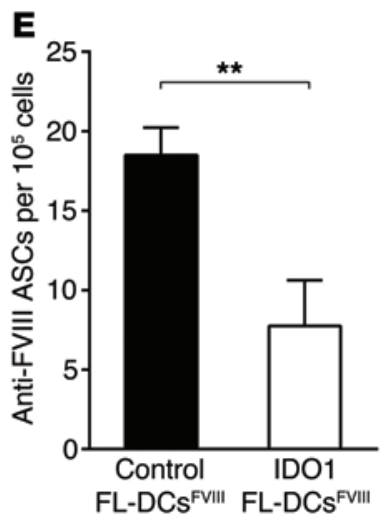

Figure 8. Ectopic ID01 expression in FL-DCs increases FVIII-specific Tregs in hemophilia A patients and suppresses inhibitor titers. (A) ID01 transcript expression of human FL-DCs transfected with human IDO1 or mock (control) plasmid after 48 hours; $n=5$. Data represent mean \pm SD of 3 experiments. ${ }^{* * *} P<0.001$, Student's $t$ test. (B) ID01 protein expression in DCs transfected as in A, as determined by immunoblotting. Representative results from 1 inhibitor-positive hemophilic patient. Data represent mean $\pm \operatorname{SD}(n=5)$; ${ }^{* *} P<0.001$, Student's $t$ test (mock vs. IDO1 transfection). (C) Representative results of the frequency of $\mathrm{CD} 4^{+} \mathrm{FOXP3} 3^{+}$cells (top right quadrants) cultured for 5 days with control (mock) or IDO1-transfected FL-DCs from inhibitor-positive patients, either as such or loaded with rhFVIII. Representative results from 1 experiment of 3 . (D) Frequency of CD4 ${ }^{+} \mathrm{FOXP3}^{+}$cells among CD4 ${ }^{+} \mathrm{T}$ cells cultured as in C. Mean \pm SD (3 independent experiments). $n=5$. ${ }^{*} P<0.05$; ${ }^{* *} P<0.001$, Student's $t$ test. (E) Enumeration of FVIII-specific IgG-secreting plasma cells, assessed by ELISpot, in B cell cultures from inhibitor-positive patients treated for 5 days with autologous CD4 ${ }^{+}$T cells and rhFVIII-pulsed FL-DCs, transfected with either control (mock) or IDO1-specific siRNA. $n=5$. Data represent mean \pm SD of 3 independent experiments. ${ }^{*} P<0.01$, Student's $t$ test.

increase in FVIII-specific CD4 ${ }^{+} \mathrm{FOXP}^{+}$Tregs (Figure 8, C and D). Those cells were capable of suppressing the differentiation of FVIII-specific memory B cells into FVIII-specific antibody-producing plasma cells in vitro (Figure 8E). Thus, restoration of IDO1 expression in DCs from inhibitor-positive patients induces FVIIIspecific Tregs restraining inhibitor production.

\section{Discussion}

The development of alloantibody inhibitors against FVIII represents the most serious complication of hemophilia care. Inhibitors tend to develop early in the course of treatment, in about $20 \%$ to $30 \%$ of patients with severe hemophilia and on replacement therapy with an FVIII product. As such, inhibitors represent a huge burden for affected patients and families, and they pose a large economic burden for a chronic disease. Research efforts have long attempted to identify the conditions favoring inhibitor development and optimize therapy, so as to prevent or eradicate inhibitors. Several factors, both genetic and environmental in nature, are known to be associated with inhibitor formation, including major F8 gene defects, family history, and non-mixed European race as well as disease severity, age at first treatment, intensity of early treatment, use of prophylaxis, and product choice $(3,5,37)$. Although lack of central tolerance to FVIII is the major predisposing factor to inhibitor formation, evidence indicates that both central and peripheral mechanisms of immunological tolerance are key to opposing inhibitor occurrence in hemophilic patients and in healthy subjects as well. IDO1 is a master regulator of peripheral tolerance driven by DCs, which preside over immune homeostasis in adult life $(38,39)$, and defective IDO1 function in DCs might thus contribute to inhibitor development.

In our cross-sectional study of patients with severe hemophilia A, we found a strong correlation between IDO1 functionality and inhibitor status. Thirty-six (72\%) inhibitor-negative and 16 (36\%) inhibitor-positive patients were capable of upregulating IDO1 in response to a prototypical danger signal, namely, a synthetic CpG-rich oligonucleotide, recognized by TLR9, which acts physiologically as a nucleic acid sensor. The unadjusted OR for inhibitors in patients not competent for IDO1 was 4.57, and it was 8.11 when adjusted for family history, previous treatment with plasma-derived or recombinant FVIII, and previous use of single or multiple concentrates. IDO1 transcripts, protein expression, and kynurenine production in response to TLR9 activation were 
all deficient in the inhibitor-positive patients relative to their negative counterparts. Lack of IDO1 induction in response to TLR9 activation was not explained by altered TLR9 expression or by any known genetic determinant of variability in TLR9 function.

The correlation between defective TLR9-driven IDO1 induction and FVIII-specific antibody production was confirmed in hemophilic mice, with or without functional IDO1. We found that TLR9 stimulation by any CpG-ODN dosage elicited inhibitors and proinflammatory cytokines in hemophilic mice lacking IDO1, in marked contrast to what was observed in hemophilic yet IDO1-competent mice, where a low CpG-ODN dosage had no effect and a higher dosage $\left(\mathrm{CpG}_{\mathrm{H}}\right)$ instead exerted an inhibitory effect on FVIII-specific antibody production. The requirement for functional IDO1 in the protection afforded by $\mathrm{CpG}_{\mathrm{H}}$ could be traced to the production of tryptophan catabolites. The defective IDO1 function in mice was, in fact, obviated by supplemental L-kynurenine, the first byproduct of tryptophan catabolism by IDO1 along the so-called kynurenine pathway. Replacement therapy with L -kynurenine prevented the generation of anti-FVIII antibodies, an effect likely involving suppression of proinflammatory cytokine production, induction of antiinflammatory TGF- $\beta$ and IL-10, and regulation of FVIII-specific B cell development. Noticeably, the effect of supplemental L-kynurenine also required a functional AhR in the host, which is physiologically activated by L-kynurenine to avoid hyperinflammatory conditions (24). In different experimental systems, the combined effects of tryptophan starvation and L-kynurenine downregulate the $\mathrm{T}$ cell receptor $\zeta$ chain and induce a regulatory phenotype in naive $\mathrm{T}$ cells via $\mathrm{AhR}$ engagement in DCs $(23,40,41)$.

In all the experimental models tested so far, lack of IDO1 competence does not result, per se, in spontaneous autoimmune pathology. Yet mice treated with IDO1 inhibitors become refractory to acquired tolerance induction $(42,43)$. Under conditions in which self tolerance is broken, IDO1 inhibition causes severe exacerbation of immune-related diseases, such as allergic asthma (15), inflammatory bowel disease (44), and autoimmune encephalomyelitis (45). Conversely, MHC-mismatched mouse allografts transfected with $I d o 1$ are protected from rejection (46), and transfection of the FVIII-encoding gene together with IDO1 results in markedly lower inhibitor titers and prolonged FVIII expression in FVIII KO mice. In particular, using transposon-based human F8 and IDO1 gene delivery in the liver, the authors of that study observed long-term therapeutic FVIII expression and significantly reduced inhibitor titers when the 2 genes were codelivered (47). Interestingly, CpG-ODN administration inhibits FVIII-specific antibody response in vivo in FVIII-deficient mice (21) via a mechanism known to induce IDO1 and/or promote tolerogenic responses through tryptophan catabolism (42).

Complementing a long-established paradigm - that the primary function of the mammalian immune system is to discriminate self from nonself - a "danger model" has been introduced in immunology, making the suggestion that the immune system will respond to molecules, whether foreign in nature or self antigens, that cause tissue damage and the release of immune-stimulating alarm signals (48). As a consequence, if proteins (or processed peptides thereof) are encountered at a time when other factors provoke damage, the immune system may associate those pro- teins with the damage signals, even if the 2 events are not causally linked, and initiate a generalized defense response (49). In hemophilia, based on clinical observations of an association between inhibitor development and events such as bleeding, infections, and surgery, it has been proposed that immunological danger signals in concomitance with supplemental FVIII can promote FVIIIspecific immune responses $(50,51)$. Avoiding danger signals with an appropriate prophylaxis regimen would, in contrast, reduce inhibitor incidence rate (52).

Tregs play an important role in the maintenance of homeostasis and the prevention of inflammatory diseases. Although most studies have focused on the role of Tregs in T cells and T cell-mediated diseases, these cells also directly affect B cells and antibody production $(53,54)$. Follicular Treg subsets have been identified as the main populations that control local Th cell-mediated autoantibody production $(55,56)$. In vitro, we found that forced IDO1 expression in DCs from inhibitor-positive patients restored FVIIIspecific Treg generation and that the induced $\mathrm{CD}^{+} \mathrm{FOXP}^{+}$cells were capable of suppressing the differentiation of FVIII-specific memory B cells into FVIII antibody-producing plasma cells.

Drug agonists of TLR9 have been proven in clinical trials to be effective against infections, allergies, malignant neoplasms, and autoimmunity $(57,58)$. Our data show that danger signals sensed by TLRs have an impact on the immune system of hemophilic patients, which, in turn, could affect their ability to regulate immunity through acquired tolerance mechanisms. Our results point, in fact, to different outcomes of TLR9 activation, which translates into the sustenance of inflammatory responses in inhibitor-positive subjects, as opposed to the fostering of regulatory reactions in their negative counterparts. This could affect the balance between tolerance and immunity, when administration of a nonself protein (such as FVIII) and inflammation triggered by danger signals occur simultaneously.

On specifically considering hemophilic patients, 2 limitations should be considered when appraising the results of this study. First, to maximize the internal validity of our setting, we sought to eliminate known variables influencing IDO1 expression by excluding patients with chronic and acute infectious or inflammatory diseases or on immunoactive therapy. Our results should not be generalized to patient populations with different characteristics from those investigated in this study. Second, we cannot exclude that, in some cases, trace amounts of protein could have been produced and partial central tolerance might have been established. However, this is highly unlikely because we included only patients with $F 8$ mutations known to induce a complete deficit in circulating FVIII polypeptides (that is, large deletions, inversions, nonsense mutations). Additionally, multivariable logistic regression showed no effect of mutation type - i.e., different forms of $F 8$ null mutation - on IDO1 function. For example, it has recently been suggested that patients with intron 22 inversions - the underlying F8 mutation in about $50 \%$ of individuals with severe hemophilia $\mathrm{A}$ - can permit, at least in a portion of them, partial intracellular production of FVIII protein that could contribute to FVIII-specific unresponsiveness through central tolerance mechanisms (8). In addition, one might think that the combination of stochastic processes with other mechanisms of peripheral tolerance, such as heme oxygenase-1 (59), the HLA system (60), and an individual's immune gene 
profile (37), could also contribute to explaining why not all patients with defective IDO1 produce inhibitors and, conversely, why not all patients without the IDO1 defect are inhibitor negative.

To date, there are no prospective studies assessing IDO1 expression in hemophilic patients. Longitudinal cohort studies collecting serial samples commencing before any exposure to FVIII, and definitely before and after inhibitor development, are required to verify that dysfunctional IDO1 detection could be used as a predictor of inhibitor development.

In several experimental settings $(13,24)$, L-kynurenine-based immunotherapy has shown therapeutic efficacy in reinstalling tolerance. Although the long-term safety and effectiveness of strategies involving peripheral tolerance manipulation need verification in humans, our current results could form a basis for further progress toward novel strategies aimed at limiting FVIII alloantibody production and establishing tolerance to FVIII products. Ideally, this could apply to patients at the beginning of prophylaxis, to reduce the incidence rate of inhibitors, or in patients undergoing ITI, to increase the odds of success.

\section{Methods}

Patients and outcomes in primary analysis. Severe hemophilia A patients (plasma FVIII $<0.01 \mathrm{IU} / \mathrm{ml}$ ) who had developed high-titer inhibitors (historical inhibitor peak $>5$ Bethesda units $[\mathrm{BU}] / \mathrm{ml}$ ) were enrolled in 6 hemophilia centers in Italy from July 2011 to March 2013. Age-matched, inhibitor-negative patients were included as controls if consistently inhibitor free after at least 150 exposure days. We defined inhibitor-positive patients as those meeting the criteria of at least 2 positive antibody titers combined with a decreased FVIII recovery within the first 50 exposure days. FVIII recovery was considered as being decreased if less than $66 \%$ of the expected level. All subjects in this study, whether inhibitor positive or controls, carried $F 8$ mutations expected to cause complete absence of functional FVIII protein namely, large deletions, nonsense mutations, or intron 1 and 22 inversions - which are all thought to prevent central tolerance to FVIII (51). To reduce any potential confounding by comorbidity, we excluded patients with known acute or chronic inflammatory, infectious, or autoimmune diseases or who were on immunoactive drugs. Subclinical, active inflammatory conditions were excluded by measurements of C-reactive protein. Plasma CRP levels were measured by highsensitivity particle-enhanced immunonephelometry (CardioPhase; Siemens Healthcare Diagnostics). Patients with active bleeding or with more than 1 bleeding episode in the previous 3 months were also excluded. Blood samples were collected using routine techniques after a washout period of 3 days for FVIII recipients. Plasma samples were analyzed for FVIII inhibitory antibodies using the Bethesda assay, as detailed elsewhere (61). Each patient was tested at least 3 times. Date of birth, ethnicity, bleeding and treatment history, family history of inhibitors, mutation, and inhibitor history were all collected. Inhibitor occurrence was defined as the presence of at least 2 separate positive antibody titers and decreased FVIII recovery. Inhibitor titer was determined in each center by the Bethesda assay with the Nijmegen modification; positive titers were confirmed centrally with the same method. IDO competence was defined as the condition whereby consistent and concordant increases (that is, fold changes exceeding the respective baseline levels by $>20 \%$ ) could be induced in IDO transcript, protein, and functional expressions.
Mice and in vivo treatments. Hemophilic $F 8^{-/-}$(C57BL/6; 129S4F8tm1Kaz/J) mice and $\mathrm{Ido1}^{-/}$mice were originally obtained from The Jackson Laboratory. $F 8$ and Ido1 DKO mice were generated in our animal facility by crossing hemophilic $\mathrm{F}^{-/-}$and $\mathrm{IdO}^{-/-}$mice, both on a C57BL/6 background. Offspring lacking both $F 8$ and $I d o 1$ were genotyped by PCR using the following primers: 5'-TGTGTCCCGCCCCTTCCTT-3' (Neo sense), 5'-TGCAAGGCCTGGGCTTATTT (F8 WT sense), GAGCAAATTCCTGTACTGAC (F8 WT antisense); 5'-TGGAGCTGCCCGACGC-3' (Ido1 WT sense), 5'-TACCTTCCGAGCCCAGACAC-3' (Ido1 WT antisense). In all experiments, hemophilic $\mathrm{F}^{-/-}$mice were used as controls for DKO mice. All mice were male and 8 to 10 weeks old on commencing the experiments and were housed and fed under specific pathogen-free conditions. If not otherwise stated, mice received 4 intravenous doses of $200 \mathrm{ng}$ (approximately $80 \mathrm{IU} / \mathrm{kg}$ ) of rhFVIII (Kogenate; a gift from Bayer Italia S.p.A.), diluted in $200 \mu \mathrm{l} \mathrm{HBSS}$, at weekly intervals. Endotoxin-free CpG oligonucleotide, on a phosphorothioate backbone (ODN 1826; 5'-TCCATGACGTTCCTGACGTT-3') was purchased from Bio Fab Research and used in vivo at $50 \mu \mathrm{g} /$ mouse $\left(\mathrm{CpG}_{\mathrm{H}}\right)$ or $1 \mu \mathrm{g} /$ mouse $\left(\mathrm{CpG}_{\mathrm{L}}\right)$. Groups of mice received neutralizing antibodies to IL-10 (clone JES5.2A5 200 $\mu \mathrm{g} /$ mouse) or TGF- $\beta$ (clone 11D1; $100 \mu \mathrm{g} /$ mouse), or isotype controls. Antibodies (clone JES5.2A5 and clone 11D1) were purified using affinity chromatography from hybridoma supernatants that were generated by culturing the cells in IMDM containing 1\% FCS. 1-MT (5 mg per mouse; $d l$ racemic mixture; Sigma-Aldrich) was administered intraperitoneally. CH-223191 (10 mg/kg; Tocris) was administered by oral gavage starting 1 day after the first $\mathrm{CpG}$ administration and then daily for 4 weeks. Vehicle-treated groups were used as controls. Mice were tested for inhibitor concentration weekly for 4 consecutive weeks.

Blood sampling and measurements of mouse anti-FVIII antibodies. Blood was collected weekly from anesthetized mice, using uncoated microhematocrit capillary tubes via the retroorbital sinus. Blood was mixed with $1 / 10$ volume of trisodium citrate $(0.13 \mathrm{M})$, and plasma samples were isolated by centrifugation at $2,700 \mathrm{~g}$ for 15 minutes at $4^{\circ} \mathrm{C}$. Supernatants were immediately transferred to a fresh tube and stored at $-80^{\circ} \mathrm{C}$ until analysis. Total anti-FVIII antibodies were quantified by ELISA according to previously published protocols (7). Goat anti-mouse $\operatorname{IgG}_{1}, \operatorname{IgG}_{2 \mathrm{a}}, \operatorname{IgG}_{2 \mathrm{~b}}$, IgG , and IgM antibodies (Southern Biotechnology Associates) were used for revealing isotype-specific serum antibodies. Plasma samples were also analyzed for FVIII inhibitory antibodies using a 2-stage FVIII clotting assay in an automated coagulometer (Instrumentation Laboratory) according to the manufacturer's instructions. Titers (BU) were calculated as detailed elsewhere (61).

Analysis of FVIII-specific IgG-secreting cells by ELISpot. MultiScreen-IP opaque 96-well plates (High Protein Binding Immobilon-P membrane; Millipore) were coated overnight at $4^{\circ} \mathrm{C}$ with rhFVIII $(1 \mu \mathrm{g} / \mathrm{ml})$ in PBS. Plates were blocked with blocking buffer R (u-CyTech Biosciences) for 2 hours at $37^{\circ} \mathrm{C}$ in $5 \% \mathrm{CO}_{2}$. Serially diluted mouse splenic cells or human $\mathrm{B}$ cells were added to the plates in triplicate and cultured for 16 hours at $37^{\circ} \mathrm{C}$ in $5 \% \mathrm{CO}_{2}$. IgG-secreting cells were revealed with biotin-coupled anti-mouse IgG antibody (Vector Laboratories) diluted 1:2,000 in dilution buffer R, followed by streptavidin-HRP solution and the 3-amino9-ethylcarbazole (AEC) coloring system (u-CyTech Biosciences). Plates were scanned, and spots were counted with an ELISpot plate reader.

Human and mouse cell isolation and treatments. PBMCs were isolated by standard techniques, using Ficoll-Paque Plus gradient centrifugation from whole blood samples diluted 1:1 with buffered saline. 
Total $\mathrm{CD}^{+}$cells were isolated by the Human $\mathrm{CD} 4^{+} \mathrm{T}$ Cell Isolation Kit (Miltenyi Biotech). DCs were isolated using the Blood Dendritic Cell Isolation Kit II (Miltenyi Biotech) and the MACS system. Monocytes and B cells were isolated from PBMCs with CD14 and CD19 MicroBeads, respectively, and the MACS system to a greater than 95\% purity. Cell isolation kits and MicroBeads were from Miltenyi Biotech. Human mature FL-DCs were isolated from PBMCs. Briefly, FL-DCs were obtained from purified $\mathrm{CD} 14^{+}$monocytes by culturing cells in Iscove-modified medium for 7 days in the presence of $50 \mathrm{ng} /$ $\mathrm{ml}$ human FLT3L (Peprotech). FACS analysis revealed that the FLDCs were $\mathrm{CD} 123^{+} \mathrm{CD} 11 \mathrm{c}^{\mathrm{lo}} \mathrm{BDCA} 2^{+}$and $\mathrm{BDCA} 4^{+}$. PBMCs or purified cells were cultured at a final concentration of $1 \times 10^{6}$ cells $/ \mathrm{ml}$ with 3 $\mu \mathrm{g} / \mathrm{ml} \mathrm{CpG-ODN} 2006$ (5'-TCGTCGTTTTGTCGTTTTGTCGTT-3'; Bio-Fab Research) or control medium alone for specific times, as indicated. Neutralization of IP-10 ( $5 \mu \mathrm{g} / \mathrm{ml}$; R\&D Systems) and IFN- $\alpha$ (5 $\mu \mathrm{g} / \mathrm{ml}$; Abcam clone Ab200) was done in vitro with specific antibodies, used in parallel with isotype controls. Murine cells were isolated from mice treated in vivo with $\mathrm{CpG}_{\mathrm{L}}, \mathrm{CpG}_{\mathrm{H}}$, or vehicle. Specifically, splenic DCs were purified using CD11c MicroBeads (Miltenyi Biotech) in the presence of EDTA to disrupt DC-T cell complexes. Cells were more than $99 \%$ CD11 $\mathrm{c}^{+}$, more than $99 \%$ MHC I-A $\mathrm{A}^{+}$, more than $98 \%$ B7-2 $2^{+}$, and less than $0.1 \% \mathrm{CD}^{+}$, and appeared to be $90 \%-95 \% \mathrm{CD} 8^{-}$, $5 \%-10 \% \mathrm{CD}^{+}$, and $1 \%-5 \% \mathrm{~B} 22 \mathrm{O}^{+}$cells. Total splenic CD $4^{+} \mathrm{T}$ and $\mathrm{B}$ cells were isolated using CD4 MicroBeads according to the manufacturer's instructions, to a greater than $95 \%$ purity. Total mouse splenic B cells were purified using a Pan B isolation kit (Miltenyi Biotech) to a greater than $98 \%$ purity. In selected experiments, antibody-producing plasma cell populations were further fractionated according to CD138 expression by means of PE-conjugated CD138 (BioLegend) followed by PE-MicroBeads (Miltenyi Biotec) to a greater than $95 \%$ purity.

Flow cytometry. In all FACS analyses, cells were treated with rat anti-CD16/32 (2.4G2) for 30 minutes at $4^{\circ} \mathrm{C}$ for blocking of Fc receptors before assaying on an LSRFortessa (BD Biosciences) flow cytometer and were analyzed by IDO1 data analysis software. For human cells, the following fluorochrome-conjugated monoclonal antibodies were used: CD4 (RPA-T4), CD25 (BC96), and FOXP3 (150D) (BioLegend); CD11c (MJ4-27G12), CD19 (LT19), CD3 (BW264/56), and CD14 (TÜK4) (Miltenyi Biotech). For mouse cells, the following fluorochrome-conjugated monoclonal antibodies were used: mPDCA1 (JF05-1C2.4.1), CD19 (6D5), CD11c (N418), CD4 (GK1.5), and CD11b (M1/70.15.11.5), (Miltenyi Biotech); GL7 (GL-7), CD138 (281-2), and CD95 (15A7) (eBioscience).

Immunofluorescence. Spleens were removed and fixed in 10\% phosphate-buffered formalin, embedded in paraffin, and sectioned at $5 \mu \mathrm{m}$. Sections were then rehydrated and, after antigen retrieval in citrate buffer (10 mM, pH 6), blocked with 5\% BSA in PBS and stained with PE-CD11c (eBioscience) and polyclonal anti-IDO antibody $(5 \mu \mathrm{g} / \mathrm{ml})$, followed by FITC-conjugated secondary antibody (24) (Sigma-Aldrich). All sections were incubated overnight at $4^{\circ} \mathrm{C}$. Cells were counterstained with DAPI (Molecular Probes, Invitrogen) to detect nuclei. Immunofluorescence microscopy was performed on an Olympus microscope (BX51) and analyzed by AnalySIS image processing software.

Immunohistochemistry. Formalin-fixed paraffin-embedded spleens were cut at $4 \mu \mathrm{m}$, deparaffinized with xylene, and rehydrated in a graded ethanol series. Antigen retrieval was obtained by boiling for 1.5 hours in $10 \mathrm{mM}$ citric acid buffer ( $\mathrm{pH}$ 6.0), and depletion of endogenous peroxidase was accomplished by treatment with $3 \% \mathrm{H}_{2} \mathrm{O}_{2}$.
Sections were washed with TBS, $\mathrm{pH}$ 7.4, incubated for 1 hour with blocking buffer (TBS containing 0.01\% Tween-20 [T-TBS] and 10\% HS), and probed with the anti-IDO1 (24) antibody in blocking buffer. After overnight incubation at $4^{\circ} \mathrm{C}$, the sections were incubated with HRP-conjugated anti-rabbit IgG antibody (Santa Cruz Biotechnology Inc., 1:500). Sections were incubated with $0.01 \% \mathrm{DAB}$ and $0.006 \%$ $\mathrm{H}_{2} \mathrm{O}_{2}$ in $50 \mathrm{mM}$ Tris- $\mathrm{HCl}, \mathrm{pH}$ 7.4. Nuclei were counterstained with hematoxylin. The slices were then dehydrated, mounted with Eukitt mounting medium (Electron Microscopy Sciences), and analyzed and photographed with a bright field microscope (Olympus BX51) equipped with a digital camera.

Analysis of mouse and human IDO1 and L-kynurenine determination. IDO1 expression was investigated in total PBMCs or purified cell subsets $\left(1 \times 10^{6} / \mathrm{ml}\right.$ in 24-well plate) isolated from hemophilic patients with or without inhibitor after culture with CpG-ODN $2006(3 \mu \mathrm{g} / \mathrm{ml})$ or medium as a control for 48 hours. Human IDO1 expression was measured by sequential immunoblotting with anti-IDO1 (10.1) (Millipore) and anti- $\beta$-tubulin (Sigma-Aldrich) for normalization. Ratios of IDO1 to $\beta$-tubulin were determined by ImageJ software (http:// imagej.nih.gov/ij/). Murine IDO1 was investigated using a rabbit antimouse IDO1 antibody raised in our laboratory (24) and further purified by affinity chromatography. Total splenocytes were isolated from F8 KO or DKO mice, either untreated or treated in vivo with $\mathrm{CpG}_{\mathrm{H}}$, $\mathrm{CpG}_{\mathrm{L}}$, or vehicle on day 14 ; densitometry ratios of IDO1 to $\beta$-tubulin bands were determined by ImageJ software. Measurements of IDO1 functional activity in terms of L-kynurenine production in plasma or cell supernatants were as described $(11,24)$. Further details of L-kynurenine determination are provided in Supplemental Methods.

GC histochemical analysis. GCs were identified using PNA lectin cytochemistry combined with anti-mouse IgD immunohistochemistry. Frozen sections of spleens (8- $\mu \mathrm{m}$ thick) were fixed in cold acetone and allowed to dry. The sections were rehydrated using 5\% BSA in PBS for 20 minutes, followed by the addition of biotinylated PNA (catalog B-1075; Vector Laboratories), and incubated for 45 minutes. After washing, lectin binding was detected by ExtrAvidin-Alkaline Phosphatase (catalog E-2636; Sigma-Aldrich) and visualized using NBT-BCIP chromogen in the presence of $2-\mathrm{mg} / \mathrm{ml}$ levamisol (SigmaAldrich). Endogenous peroxidase activity was blocked using $1 \mathrm{mg} /$ $\mathrm{ml}$ phenyl-hydrazine- $\mathrm{HCl}$ in PBS for 20 minutes, followed by washing and saturation with 5\% BSA in PBS. Next, the sections were incubated with a rat monoclonal antibody to mouse IgD (catalog 553438; BD Biosciences). Binding was detected by HISTOLS anti-rat IgG reagent (Izinta) and visualized with $\mathrm{DAB}-\mathrm{H}_{2} \mathrm{O}_{2}$ (DAKO). The size of individual GCs was defined as the blue PNA-positive cluster within an anti-IgD-reactive mantle zone and measured by AnalySIS software. In 5 consecutive sections, cut from 4 sectioning planes $250 \mu \mathrm{m}$ apart, at least $120 \mathrm{GC}$ areas were measured in each spleen, and their size distribution was plotted in 2,000 $\mu \mathrm{m}^{2}$ increments using the Excel Analysis ToolPak histogram tool.

IDO1 silencing and transfection. These procedures have been described previously (33). Briefly, the siRNA sequences specific for human IDO1 (sense, 5'-CCACGAUCAUGUGAACCCAtt-3'; antisense, 5'-UGGGUUCACAUGAUCGUGGat-3') were selected, synthesized, and annealed by the manufacturer (Ambion). Additional sets of siRNA sequences specific for human IDO1 (sense, 5'-UCACCAAAUCCACGAUCAUUU-3'; antisense, 5'-PUAUGCGAAGAACACUGAAAUU-3'; and, sense, 5'-UUUCAGUGUUCUUCGCAUAUU-3'; antisense, 
5'-PUAUGCGAAGAACACUGAAAUU-3') were from Dharmacon. siCONTROL Nontargeting Pool (D-001810-10-05, Dharmacon) was used as a control. For transfection, siRNAs $(5 \mu \mathrm{g})$ in $30 \mu \mathrm{l}$ of transfection buffer (20 mM HEPES, $150 \mathrm{mM} \mathrm{NaCl}, \mathrm{pH}$ 7.4) were pipetted into a sterile Eppendorf tube. In a separate polystyrene tube, $6.7 \mu \mathrm{g}$ of 1,2 dioleoyl-3-trimethylammonium-propane (DOTAP) was mixed with $30 \mu \mathrm{l}$ of transfection buffer, and then both solutions were mixed gently by pipetting several times. After incubation at room temperature for 20 minutes, the mixture was added to $1 \mathrm{ml}$ of complete medium containing $10^{6}$ cells and incubated for 24 hours at $37^{\circ} \mathrm{C}$, either alone or in the presence of CpG-ODN. Cells were recovered, washed, and immediately used for in vivo experiments. siRNA treatment resulted in the complete disappearance of the relevant transcripts at 24 to 48 hours. Control treatments consisted of cells treated with negative control siRNA (Ambion). Efficiency of siRNA transfection was evaluated in terms of percentage of cells labeled with Cy3-negative control (Ambion). Transfection rates always exceeded 90. For IDO1 overexpression, the human IDO1 gene was cloned (kpnI/NotI) into the pEZ_MO2 expression plasmid. The empty vector was used as mock control. For transfection of plasmidic DNA, $20 \mu \mathrm{g}$ of DOTAP was mixed with 93.4 $\mu \mathrm{l}$ of transfection buffer (20 mM HEPES, $150 \mathrm{mM} \mathrm{NaCl}, \mathrm{pH} 7.4$ ) into a sterile Eppendorf tube; in a separate tube, $5 \mu$ g plasmidic DNA (i.e., IDO1 or mock) in $50 \mu \mathrm{l}$ of transfection buffer was pipetted, and then solutions were mixed gently and incubated at room temperature for 30 minutes. At the end of the incubation, the mixture was added to $10^{6}$ cells resuspended in $1 \mathrm{ml}$ of complete medium for overnight culture.

Supplemental Methods. DNA isolation and SNP selection and genotyping, ELISA and assessments of cytokine production, real-time RT-PCR, and details of L-kynurenine determination are described in Supplemental Methods.

Statistics. Standard descriptive statistics were used to describe baseline patient characteristics and results of induction experiments. Two-tailed Student's $t$ test and $\chi^{2}$ statistics were used to compare means and proportions. $P$ values of less than 0.05 were considered significant. In the murine experiments, independent sample $t$ test was used for results expressed as continuous variables, ANOVA test was used when more than 1 group was compared, followed by Bonferroni's multiple comparison test or Dunnett test, as appropriate. All $P$ values were calculated on a 2-tail hypothesis. All $n$ values were computed by power analysis to yield a power of at least $80 \%$ with an $\alpha$-level of 0.05. GraphPad Prism version 6.0 was used for all analyses. Two sets of logistic regression model were used with inhibitor development or IDO1 competence, respectively, as dependent variables and putative risk factors for inhibitor development as independent variables to identify any significant associations. We assessed the effect of family history of inhibitors, previous use of recombinant concentrate, previous use of multiple concentrates, and type of F8 mutation. We stated a priori to adjust the final model for variables significantly associated with either inhibitor development or IDO1 competence. Our hypothesis was that lack of IDO1 competence is associated with an increased risk of inhibitors. We investigated the strength of the association in terms of OR of inhibitor positivity for IDO1incompetent as compared with IDO1-competent, as well as of an OR of having cleared the inhibitor for IDO1-competent as compared with IDO1-incompetent patients. Finally, in a post hoc exploratory analysis exploiting the power of the entire sample size, we tested, in an ordinal logistic regression model, the association between IDO1 competence and inhibitor status, defined as negative, previous (that is, positive in the past but negative at present), or positive. Regression analysis was performed with Stata, version 11. Polymorphisms were analyzed by estimating the Hardy-Weinberg equilibrium using the expectation-maximization algorithm, as implemented in Haploview, version 4.2, software. Genotype distributions among hemophilic patients with distinct patterns of IDO1 competence were compared using the Freeman-Halton extension of the Fisher exact probability test for a 2-rows by 3-columns contingency table.

Study approval. All animal protocols were approved and conducted in accordance with the University of Perugia Bioethical Committee's guidelines (protocol \#2012-035). Informed consent was obtained before enrollment from patients according to a protocol approved by the Federico II University Ethical Committee (protocol \#152/11), in compliance with the Declaration of Helsinki.

\section{Acknowledgments}

This work was supported by funding from the Italian Association for Cancer Research (AIRC) (to P. Puccetti), the Italian Ministry of Health in association with Regione dell'Umbria (GR-201102346890 to D. Matino), Bayer Grants4Target Focus (2012-030630 to A. Iorio, F. Fallarino, and D. Matino), a Bayer Early Career Investigator Award (to D. Matino), and a Bayer Special Project Award (to F. Fallarino). The financial support of Telethon - Italy (GG14042) is likewise gratefully acknowledged. We thank C. Cunha and A. Carvalho for performing SNP analyses.

Address correspondence to: Alfonso Iorio, HIRU CRL-140, Clinical Epidemiology and Biostatistics, McMaster University, 1280 Main Street West, Hamilton, Ontario, Canada. Phone: 905.525.9140, ext. 22421; E-mail: iorioa@mcmaster.ca.
1. Manco-Johnson MJ, et al. Prophylaxis versus episodic treatment to prevent joint disease in boys with severe hemophilia. $N$ Engl J Med. 2007;357(6):535-544.

2. Leissinger C, et al. Anti-inhibitor coagulant complex prophylaxis in hemophilia with inhibitors. N Engl JMed. 2011;365(18):1684-1692.

3. Astermark J, Lacroix-Desmazes S, Reding MT. Inhibitor development. Haemophilia. 2008;14(suppl 3):36-42.

4. Iorio A, et al. Rate of inhibitor development in previously untreated hemophilia A patients treated with plasma-derived or recombinant factor
VIII concentrates: a systematic review. J Thromb Haemost. 2010;8(6):1256-1265.

5. Gouw SC, et al. Factor VIII products and inhibitor development in severe hemophilia A. N Engl J Med. 2013;368(3):231-239.

6. Kyewski B, Klein L. A central role for central tolerance. Annu Rev Immunol. 2006;24:571-606.

7. Waters B, Lillicrap D. The molecular mechanisms of immunomodulation and tolerance induction to factor VIII. J Thromb Haemost. 2009;7(9):1446-1456.

8. Pandey GS, et al. Endogenous factor VIII synthesis from the intron 22-inverted F8 locus may modulate the immunogenicity of replacement therapy for hemophilia A. Nat Med. 2013;19(10):1318-1324.

9. Krudysz-Amblo J, et al. Quantitation of antifactor VIII antibodies in human plasma. Blood. 2009;113(11):2587-2594.

10. Andre S, et al. A cellular viewpoint of anti-FVIII immune response in hemophilia A. Clin Rev Allergy Immunol. 2009;37(2):105-113.

11. Fallarino F, et al. Modulation of tryptophan catabolism by regulatory T cells. Nat Immunol. 2003;4(12):1206-1212.

12. Pallotta MT, et al. Indoleamine 2,3-dioxygenase 
is a signaling protein in long-term tolerance by dendritic cells. Nat Immunol. 2011;12(9):870-878.

13. Romani $\mathrm{L}$, et al. Defective tryptophan catabolism underlies inflammation in mouse chronic granulomatous disease. Nature. 2008;451(7175):211-215.

14. Chung DJ, et al. Indoleamine 2,3-dioxygenaseexpressing mature human monocyte-derived dendritic cells expand potent autologous regulatory T cells. Blood. 2009;114(3):555-563.

15. Hayashi T, et al. Inhibition of experimental asthma by indoleamine 2,3-dioxygenase. JClin Invest. 2004;114(2):270-279.

16. Baban B, et al. IDO activates regulatory $\mathrm{T}$ cells and blocks their conversion into Th17-like T cells. J Immunol. 2009;183(4):2475-2483.

17. Moseman EA, et al. Human plasmacytoid dendritic cells activated by $\mathrm{CpG}$ oligodeoxynucleotides induce the generation of $\mathrm{CD} 4{ }^{+} \mathrm{CD} 25^{+}$regulatory T cells. JImmunol. 2004;173(7):4433-4442.

18. Ehlers M, Ravetch JV. Opposing effects of Tolllike receptor stimulation induce autoimmunity or tolerance. Trends Immunol. 2007;28(2):74-79.

19. Fallarino F, Puccetti P. Toll-like receptor 9-mediated induction of the immunosuppressive pathway of tryptophan catabolism. Eur J Immunol. 2006;36(1):8-11.

20. Mellor AL, Baban B, Chandler PR, Manlapat A, Kahler DJ, Munn DH. Cutting edge: $\mathrm{CpC}$ oligonucleotides induce splenic CD19+ dendritic cells to acquire potent indoleamine 2,3-dioxygenase-dependent $\mathrm{T}$ cell regulatory functions via IFN Type 1 signaling. J Immunol. 2005;175(9):5601-5605.

21. Allacher P, Baumgartner CK, Pordes AG, Ahmad RU, Schwarz HP, Reipert BM. Stimulation and inhibition of FVIII-specific memory B-cell responses by CpG-B (ODN 1826), a ligand for Toll-like receptor 9. Blood. 2011;117(1):259-267.

22. Volpi C, et al. High doses of CpG oligodeoxynucleotides stimulate a tolerogenic TLR9-TRIF pathway. Nat Commun. 2013;4:1852.

23. Fallarino F, et al. The combined effects of tryptophan starvation and tryptophan catabolites down-regulate $\mathrm{T}$ cell receptor zeta-chain and induce a regulatory phenotype in naive $\mathrm{T}$ cells. JImmunol. 2006;176(11):6752-6761.

24. Bessede A, et al. Aryl hydrocarbon receptor control of a disease tolerance defence pathway. Nature. 2014;511(7508):184-190.

25. Nguyen NT, et al. Aryl hydrocarbon receptor negatively regulates dendritic cell immunogenicity via a kynurenine-dependent mechanism. Proc Natl Acad Sci U S A. 2010;107(46):19961-19966.

26. Su RJ, et al. Suppression of the immune response to FVIII in hemophilia A mice by transgene modified tolerogenic dendritic cells. Mol Ther. 2011;19(10):1896-1904.

27. Qadura M, et al. Reduction of the immune response to factor VIII mediated through tolerogenic factor VIII presentation by immature dendritic cells. JThromb Haemost. 2008;6(12):2095-2104.

28. Sule G, Suzuki M, Guse K, Cela R, Rodgers JR, Lee B. Cytokine-conditioned dendritic cells induce humoral tolerance to protein therapy in mice. Hum Gene Ther. 2012;23(7):769-780.

29. MacLennan IC. Germinal centers. Annu Rev Immunol.1994;12:117-139.

30. Liu YJ, Arpin C. Germinal center development. Immunol Rev. 1997;156:111-126.

31. Sun SC, Chang JH, Jin J. Regulation of nuclear factor-kappaB in autoimmunity. Trends Immunol. 2013;34(6):282-289.

32. Oeckinghaus A, Hayden MS, Ghosh S. Crosstalk in NF- $\mathrm{KB}$ signaling pathways. Nat Immunol. 2011;12(8):695-708.

33. Grohmann U, et al. Reverse signaling through GITR ligand enables dexamethasone to activate IDO in allergy. Nat Med. 2007;13(5):579-586.

34. Puccetti P, Grohmann U. IDO and regulatory $T$ cells: a role for reverse signalling and noncanonical NF-kB activation. Nat Rev Immunol. 2007;7(10):817-823

35. Belladonna ML, Orabona C, Grohmann U, Puccetti P. TGF- $\beta$ and kynurenines as the key to infectious tolerance. Trends Mol Med. 2009;15(2):41-49.

36. Tas SW, et al. Noncanonical NF- $\mathrm{kB}$ signaling in dendritic cells is required for indoleamine 2,3-dioxygenase (IDO) induction and immune regulation. Blood. 2007;110(5):1540-1549.

37. Astermark J, et al. The polygenic nature of inhibitors in hemophilia A: results from the Hemophilia Inhibitor Genetics Study (HIGS) Combined Cohort. Blood. 2013;121(8):1446-1454.

38. Fallarino F, Grohmann U, Puccetti P. Indoleamine 2,3-dioxygenase: from catalyst to signaling function. Eur J Immunol. 2012;42(8):1932-1937.

39. Munn DH, Mellor AL. Indoleamine 2,3 dioxygenase and metabolic control of immune responses. Trends Immunol. 2013;34(3):137-143.

40. Quintana FJ. The aryl hydrocarbon receptor: a molecular pathway for the environmental control of the immune response. Immunology. 2013;138(3):183-189.

41. Mezrich JD, Fechner JH, Zhang X, Johnson BP, Burlingham WJ, Bradfield CA. An interaction between kynurenine and the aryl hydrocarbon receptor can generate regulatory T cells. J Immunol. 2010;185(6):3190-3198.

42. Fallarino F, et al. IDO mediates TLR9-driven protection from experimental autoimmune diabetes. JImmunol. 2009;183(10):6303-6312.

43. Chen X, et al. Indoleamine 2,3-dioxygenase (IDO) is involved in promoting the development of anterior chamber-associated immune deviation. Immunol Lett. 2006;107(2):140-147.

44. Gurtner GJ, Newberry RD, Schloemann SR, McDonald KG, Stenson WF. Inhibition of indoleamine 2,3-dioxygenase augments trinitrobenzene sulfonic acid colitis in mice. Gastroenterology. 2003;125(6):1762-1773.

45. Kwidzinski E, et al. Indolamine 2,3-dioxygenase is expressed in the CNS and downregulates autoimmune inflammation. FASEB $J$. 2005;19(10):1347-1349.

46. Liu H, Liu L, Fletcher BS, Visner GA. Sleeping
Beauty-based gene therapy with indoleamine 2,3-dioxygenase inhibits lung allograft fibrosis. FASEB J. 2006;20(13):2384-2386.

47. Liu L, Liu H, Mah C, Fletcher BS. Indoleamine 2,3-dioxygenase attenuates inhibitor development in gene-therapy-treated hemophilia A mice. Gene Ther. 2009;16(6):724-733.

48. Matzinger $P$. The danger model: a renewed sense of self. Science. 2002;296(5566):301-305.

49. Matzinger P. The evolution of the danger theory. Interview by Lauren Constable, Commissioning Editor. Expert Rev Clin Immunol. 2012;8(4):311-317.

50. Lacroix-Desmazes S, Navarrete AM, Andre S, Bayry J, Kaveri SV, Dasgupta S. Dynamics of factor VIII interactions determine its immunologic fate in hemophilia A. Blood.2008;112(2):240-249.

51. Reipert BM, van Helden PM, Schwarz HP, Hausl C. Mechanisms of action of immune tolerance induction against factor VIII in patients with congenital haemophilia A and factor VIII inhibitors. Br J Haematol. 2007;136(1):12-25.

52. Coppola A, Tagliaferri A, Franchini M. Searching for the role of primary prophylaxis in preventing inhibitor development in hemophilia A. J Thromb Haemost. 2012;10(9):1954-1960.

53. Lim HW, Hillsamer P, Banham AH, Kim CH. Cutting edge: direct suppression of $B$ cells by $\mathrm{CD} 4^{+} \mathrm{CD} 25^{+}$regulatory T cells. JImmunol. 2005;175(7):4180-4183.

54. Wang P, Zheng SG. Regulatory T cells and B cells: implication on autoimmune diseases. Int JClin Exp Pathol. 2013;6(12):2668-2674.

55. Fujio K, Okamura T, Sumitomo S, Yamamoto K. Regulatory cell subsets in the control of autoantibody production related to systemic autoimmunity. Ann Rheum Dis. 2013;72(suppl 2):ii85-ii89.

56. Kinnunen T, et al. Accumulation of peripheral autoreactive $B$ cells in the absence of functional human regulatory T cells. Blood. 2013;121(9):1595-1603.

57. Hayashi T, Raz E. TLR9-based immunotherapy for allergic disease. Am JMed. 2006;119(10):897.e1-897.e6

58. Sparwasser T, Vabulas RM, Villmow B, Lipford $\mathrm{GB}$, Wagner $\mathrm{H}$. Bacterial CpG-DNA activates dendritic cells in vivo: $T$ helper cell-independent cytotoxic $\mathrm{T}$ cell responses to soluble proteins. Eur JImmunol. 2000;30(12):3591-3597.

59. Dimitrov JD, et al. Induction of heme oxygenase-1 in factor VIII-deficient mice reduces the immune response to therapeutic factor VIII. Blood. 2010;115(13):2682-2685.

60. Pavlova A, et al. Impact of polymorphisms of the major histocompatibility complex class II, interleukin-10, tumor necrosis factor-alpha and cytotoxic T-lymphocyte antigen- 4 genes on inhibitor development in severe hemophilia A. J Thromb Haemost. 2009;7(12):2006-2015

61. Verbruggen B, Novakova I, Wessels H, Boezeman J, van den Berg M, Mauser-Bunschoten E. The Nijmegen modification of the Bethesda assay for factor VIII:C inhibitors: improved specificity and reliability. Thromb Haem. 1995;73(2):247-251. 